OPEN ACCESS

Edited by:

Ruiwen Zhang,

University of Houston, United States

Reviewed by:

Jinjun Hou,

Shanghai Institute of Materia Medica

(CAS), China

Bing-Liang Ma,

Shanghai University of Traditional

Chinese Medicine, China

Yasuhito Uezono,

Jikei University School of Medicine,

Japan

Qingying Zhang,

Peking University Health Science

Centre, China

*Correspondence:

Hirotaka Kushida

kushida_hirotaka@

mail.tsumura.co.jp

Specialty section:

This article was submitted to

Ethnopharmacology,

a section of the journal

Frontiers in Pharmacology

Received: 31 March 2021

Accepted: 29 June 2021

Published: 14 July 2021

Citation:

Kushida $\mathrm{H}$, Matsumoto $\mathrm{T}$ and

Ikarashi Y (2021) Properties,

Pharmacology, and Pharmacokinetics of Active Indole and Oxindole Alkaloids

in Uncaria Hook.

Front. Pharmacol. 12:688670.

doi: 10.3389/fphar.2021.688670

\section{Properties, Pharmacology, and Pharmacokinetics of Active Indole and Oxindole Alkaloids in Uncaria Hook}

\author{
Hirotaka Kushida*, Takashi Matsumoto and Yasushi lkarashi \\ Tsumura Kampo Research Laboratories, Kampo Research \& Development Division, Tsumura \& Co., Ibaraki, Japan
}

Uncaria Hook $(\mathrm{UH})$ is a dry stem with hook of Ucaria plant and is contained in Traditional Japanese and Chinese medicine such as yokukansan, yokukansankachimpihange, chotosan, Gouteng-Baitouweng, and Tianma-Gouteng Yin. UH contains active indole and oxindole alkaloids and has the therapeutic effects on ailments of the cardiovascular and central nervous systems. The recent advances of analytical technology led to reports of detailed pharmacokinetics of UH alkaloids. These observations of pharmacokinetics are extremely important for understanding the treatment's pharmacological activity, efficacy, and safety. This review describes properties, pharmacology, and the recently accumulated pharmacokinetic findings of $\mathrm{UH}$ alkaloids, and discusses challenges and future prospects. $\mathrm{UH}$ contains major indole and oxindole alkaloids such as corynoxeine, isocorynoxeine, rhynchophylline, isorhynchophylline, hirsuteine, hirsutine, and geissoschizine methyl ether (GM). These alkaloids exert neuroprotective effects against Alzheimer's disease, Parkinson's disease, and depression, and the mechanisms of these effects include anti-oxidant, anti-inflammatory, and neuromodulatory activities. Among the $\mathrm{UH}$ alkaloids, GM exhibits comparatively potent pharmacological activity (e.g., agonist activity at $5-\mathrm{HT}_{1 \mathrm{~A}}$ receptors). $\mathrm{UH}$ alkaloids are absorbed into the blood circulation and rapidly eliminated when orally administered. UH alkaloids are predominantly metabolized by Cytochrome P450 (CYP) and converted into various metabolites, including oxidized and demethylated forms. Regarding GM metabolism by CYPs, a gender-dependent difference is observed in rats but not in humans. Several alkaloids are detected in the brain after passing through the blood-brain barrier in rats upon orally administered. GM is uniformly distributed in the brain and binds to various channels and receptors such as the 5-HT receptor. By reviewing the pharmacokinetics of UH alkaloids, challenges were found, such as differences in pharmacokinetics between pure drug and crude drug products administration, food-influenced absorption, metabolite excretion profile, and intestinal tissue metabolism of $\mathrm{UH}$ alkaloids. This review will provide readers with a better understanding of the pharmacokinetics of $\mathrm{UH}$ alkaloids and their future challenges, and will be helpful for further research on $\mathrm{UH}$ alkaloids and crude drug products containing $\mathrm{UH}$.

Keywords: Uncaria HooK, indole alkaloid, oxindole alkaloid, pharmacokinetics, absorption, metabolism, distribution, excretion 


\section{INTRODUCTION}

Uncaria Hook (UH) is a dry stem and hook of Uncaria plant in the family Rubiaceae (Ndagijimana et al., 2013; Liang et al., 2020). Many botanical origins have been identified for UH (Zhang et al., 2015), but three origins, namely Uncaria rhynchophylla (Miq.) Miq., Uncaria sinensis (Oliv.) Havil., and Uncaria macrophylla Wall., are listed in the Japanese Pharmacopoeia. UH contains several indole and oxindole alkaloids such as corynoxeine (CX), isocorynoxeine (ICX), rhynchophylline (RP), isorhynchophylline (IRP), hirsuteine (HTE), hirsutine (HTI), and geissoschizine methyl ether (GM) (Figure 1), which have similar pharmacological neuroprotective effects against Alzheimer's disease, Parkinson's disease, and depression, and the mechanisms of these effects include anti-oxidant, antiinflammatory, and neuromodulatory activities (Pengsuparp et al., 2001; Ueda et al., 2011; Ndagijimana et al., 2013; Qi et al., 2014; Yang et al., 2020).

$\mathrm{UH}$ alkaloids are also the active components of traditional Japanese Kampo medicines such as yokukansan (YKS) (Ikarashi et al., 2018), yokukansankachimpihange (YKSCH) (Takiyama et al., 2019), and chotosan (CTS) (Yuzurihara et al., 2002) containing $\mathrm{UH}$ as a crude drug. These Kampo medicines have been approved by the Japanese Ministry of Health, Labour and Welfare (MHLW), and they are indicated for the treatment of neurosis, insomnia, and irritability and night crying in children, in addition to headache and hypertension (Ministry of Health, Labour, and Welfare MHLW, 2016). In China, Yi-Gan San (YGS), which has the same composition as YKS (Gai et al., 2014), Gouteng-Baitouweng consisting of the hook and stem of Uncaria rhynchophylla (Miq.) Miq. (Gouteng in Chinese) and the root of Pulsatilla chinensis (Bunge) Regel (Baitouweng in Chinese) (Tian et al., 2018), and Tianma-Gouteng Yin decoction/ granules consisting of 11 herbal materials (Liu et al., 2015; Zhang H. et al., 2019) are known as UH-containing crude drug products. Gouteng-Baitouweng is clinically used for convulsion, a neurological symptom associated with Parkinson's disease
(Ishikawa et al., 2006). Tianma-Gouteng Yin is one of the traditional Chinese medicines prescribed to treat Parkinson's disease like symptoms such as tremor and paralysis (Chua et al., 2012).

Many studies were carried out to date on the mechanism of pharmacological action of UH alkaloids. It was experimentally shown that CX have inhibitory effects on aortic vascular smooth muscle cells (VSMC) proliferation (Kim et al., 2008) and to promote the clearance of alpha-synuclein ( $\alpha$-syn) by inducedautophagy (Chen et al., 2014), and ICX has vasorelaxantion (Li et al., 2017). In vivo studies demonstrated that RP and/or IRP have anti-depressant and neuroprotective effects (Fu et al., 2014; Sakakibara et al., 1999). Their mechanisms included the enhancement of $\alpha$-syn clearance by induced-autophagy ( $\mathrm{Li}$ et al., 2017) and effects through central dopaminergic system (Sakakibara et al., 1999) or the central monoaminergic neurotransmitter system (Xian et al., 2017). HTI and HTE, like other UH alkaloids, were also demonstrated to possess a protective effect against neuronal death (Kanno et al., 2014). Basic in vivo and in vitro studies illustrated that GM alleviates experimental anxiety, aggressiveness, dementia, allodynia, and vasoconstriction (Watanabe et al., 2003; Matsumoto et al., 2013; Mizoguchi and Ikarashi, 2017; Ikarashi et al., 2018). Multiple actions such as serotonergic (Pengsuparp et al., 2001; Nishi et al., 2012: Ueki et al., 2013), dopaminergic (Ueda et al., 2011; Ishida et al., 2016), and adrenergic neurotransmission (Nakagawa et al., 2012), as well as neuroprotection (Kawakami et al., 2011; Kanno et al., 2014; Sun et al., 2016), are considered as the mechanisms underlying the pharmacological effects of GM (Ikarashi and Mizoguchi, 2016; Ikarashi et al., 2018).

Although much pharmacological evidence had been accumulated for UH-containing crude drug products (Egashira et al., 2001; Murakami et al., 2005; Zhao et al., 2005; Ito et al., 2013; Ikarashi and Mizoguchi, 2016; Tabuchi et al., 2017; Jiang et al., 2019), few studies had been performed on their pharmacokinetics until recently. In particular, there was little information on the pharmacokinetics of GM compared to that of

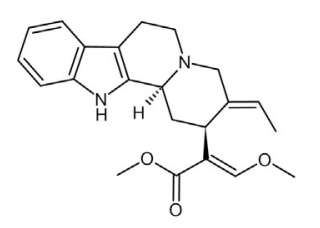

Geissoschizine methyl ether

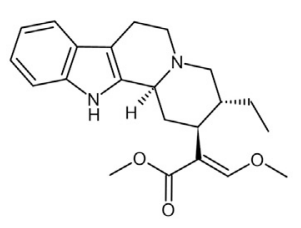

Hirsutine

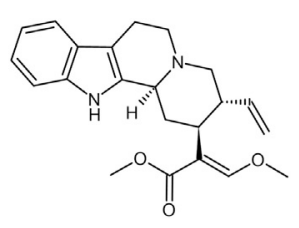

Hirsuteine

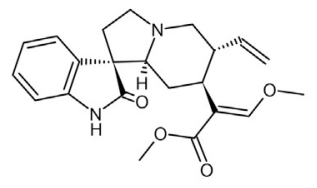

Corynoxeine

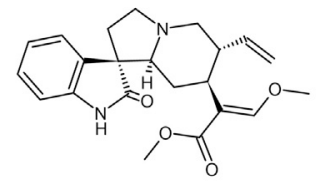

Isocorynoxeine

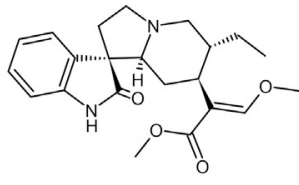

Rhynchophyline

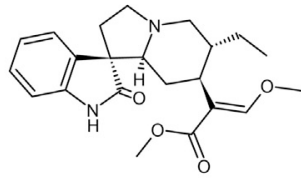

Isorhynchophyline

FIGURE 1 | Chemical structure of the main indole and oxindole alkaloids in UH. 
essential Uncaria alkaloids such as RP, IRP, CX, ICX, HTE, and HTI (Nakazawa et al., 2006; Wang et al., 2010a; Wang et al., 2010b; Wang et al., 2014a; Wang et al., 2014b; Wang et al., 2017; Zhang et al., 2017; Chen et al., 2020). However, as multiple and potent pharmacological activities of GM have become apparent, with breakthroughs of analytical technologies, pharmacokinetic information has also gradually been accumulated, such as its absorption (Ma et al., 2014; Han et al., 2019), exposure to circulation blood (Kushida et al., 2013; Gai et al., 2014; Kitagawa et al., 2015; Zhang H. et al., 2019), hepatic metabolism (Kushida et al., 2015; Matsumoto et al., 2016; Tian et al., 2018; Kushida et al., 2021), blood-brain barrier (BBB) permeability (Imamura et al., 2011), brain distribution (Mizoguchi et al., 2014; Matsumoto et al., 2020), and urinary excretion (Gai et al., 2014; Matsumoto et al., 2018).

Pharmacokinetic findings such as the absorption, distribution, metabolism, and excretion of active indole and oxindole alkaloids in the body after the oral administration of $\mathrm{UH}$-containing crude drug products are extremely important and essential information for interpreting their pharmacological activity, efficacy, and safety. Therefore, we aimed to review data on the pharmacokinetics of $\mathrm{UH}$ alkaloids accumulated in recent decades and to improve the reader's understanding of them. We also considered the challenges and future prospects of $\mathrm{UH}$ alkaloid pharmacokinetic studies.

\section{METHODOLOGY FOR COLLECTING LITERATURE}

We first retrieved studies published over the past 21 years (2000-2021) using the search terms "geissoschizine methyl ether," "corynoxeine," "isocorynoxeine," "rhynchophylline," "isorhynchophylline," "hirsuteine," and "hirsutine" in PubMed, PMC, and ScienceDirect. From the identified articles, 55 English articles describing the pharmacokinetics and pharmacology of $\mathrm{UH}$ alkaloids were selected for this review.

\section{PROPERTIES OF UH ALKALOIDS}

Seven major active indole and oxindole alkaloids are present in $\mathrm{UH}$ (Figure 1). GM has a molecular formula of $\mathrm{C}_{22} \mathrm{H}_{26} \mathrm{~N}_{2} \mathrm{O}_{3}$, a molecular weight of $366.45 \mathrm{~g} / \mathrm{mol}$, acid dissociation constant $(\mathrm{pKa})$ of 8.25 , and octanol-water partition coefficient ( $\log \mathrm{P})$ of 3.445. CX and ICX are epimers with a molecular formula of $\mathrm{C}_{22} \mathrm{H}_{26} \mathrm{~N}_{2} \mathrm{O}_{4}(382.45 \mathrm{~g} / \mathrm{mol})$, pKa of 8.03, and LogP of 0.989. RP and IRP are also epimers with a molecular formula of $\mathrm{C}_{22} \mathrm{H}_{26} \mathrm{~N}_{2} \mathrm{O}_{4}(384.47 \mathrm{~g} / \mathrm{mol})$, pKa of 8.49 , and $\log \mathrm{P}$ of 1.633 . $\mathrm{HTE}$ is a structural isomer of GM with a molecular formula of $\mathrm{C}_{22} \mathrm{H}_{26} \mathrm{~N}_{2} \mathrm{O}_{3}(366.45 \mathrm{~g} / \mathrm{mol})$, pKa of 8.37, and LogP of 2.875. HTI with a molecular formula of $\mathrm{C}_{22} \mathrm{H}_{28} \mathrm{~N}_{2} \mathrm{O}_{3}(368.47 \mathrm{~g} / \mathrm{mol})$, pKa of 8.83, and $\log \mathrm{P}$ of 3.703 (https://scifinder-n.cas.org/). To date, no transformation between GM and other UH alkaloids has been reported, although epimerization between RP and IRP and between CX and ICX has been described (Qi et al., 2015; Wang et al., 2017).
The contents of UH alkaloids in five plant origins (Uncaria rhynchophylla (Miq.) Miq., Uncaria sinensis (Oliv.) Havil., Uncaria macrophylla Wall., Uncaria hirsuta Havil, and Uncaria sessilifructus Roxb.) has been measured (Hou et al., 2018). Concerning alkaloids derived from Uncaria rhynchophylla (Miq.) Miq., seven indole and oxindole alkaloids were present $(0.0020-0.2096 \%)$. In particular, the GM content ranged from 0.0214 to $0.2096 \%$. However, GM was not present in the remaining four plants. No other alkaloids were present in Uncaria sinensis (Oliv.) Havil. and Uncaria hirsuta Havil. The contents of $\mathrm{UH}$ alkaloids in crude drug products have also been measured. The GM content in YKS extract is reportedly $0.0054 \%$ (54 $\mu \mathrm{g} / \mathrm{g}$ ) or $0.014 \%$ (Nishi et al., 2012; Kushida et al., 2021). The contents of other UH ingredients in the YKS extract comprises of CX, ICX, RP, IRP, HTE, and HTI at 0.026, 0.009, 0.027, 0.005, 0.015 , and $0.013 \%$, respectively, which are similar to the GM contents (Nishi et al., 2012).

\section{PHARMACOLOGICAL EFFECTS AND MECHANISMS}

The main indole and oxindole alkaloids in UH have been revealed to have neuroprotective effects against Alzheimer's disease, Parkinson's disease, and depression, and the mechanisms of these effects include anti-oxidant, anti-inflammatory, and neuromodulatory activities (Pengsuparp et al., 2001; Ueda et al., 2011; Ndagijimana et al., 2013; Yang et al., 2020).

The proliferation of VSMCs induced by damage to the arterial intima is an important etiological factor in vascular proliferative diseases, such as atherosclerosis and restenosis. Kim et al. (2008) reported that $\mathrm{CX}$ has inhibitory effects on platelet-derived growth factor (PDGF)-BB-induced rat aortic VSMC proliferation. Pretreatment of VSMCs with CX $(5-50 \mu \mathrm{M})$ for $24 \mathrm{~h}$ resulted in significant decrease in the cell number (25.0-88.0\%). CX $(5-50 \mu \mathrm{M})$ significantly inhibited DNA synthesis in VSMCs induced by $50 \mathrm{ng} / \mathrm{ml}$ PDGF-BB (32.8-88.0\%). Preincubation of VSMCs with CX significantly inhibited the activation of extracellular signal-regulated kinases $1 / 2$ induced by PDGFBB. The major component of Lewy bodies in patients with Parkinson's disease is a-syn, and it is believed that the impairments of the autophagy-lysosomal pathway are related to a-syn accumulation. CX-induced autophagy, which was paralleled by increased expression of the lysosomal enzyme cathepsin $\mathrm{D}$ in different neuronal cell lines, including $\mathrm{N}_{2 \mathrm{a}}$ and SHSY-5Y cells. Furthermore, by inducing autophagy, CX promoted the clearance of wild-type and A53T a-syn in inducible Pheochromocytoma (PC12) cells. CX-induced autophagy was mediated by the protein kinase $\mathrm{B} /$ mammalian target of rapamycin (Akt/mTOR) pathway (Chen et al., 2014). It has been reported that ICX, the epimer of CX, has vasorelaxant effects (Li et al., 2017). The mechanism of vasorelaxation involves the inhibition of external $\mathrm{Ca}^{2+}$ influx via L-type calcium channels and intracellular $\mathrm{Ca}^{2+}$ release via $\alpha_{1 \mathrm{~A}}$ adrenergic receptors in VSMCs as well as the involvement of $\mathrm{K}$ channels.

The major neuropathological features of Alzheimer's disease include the extracellular accumulation of amyloid- $\beta(\mathrm{A} \beta)$ peptide 
and intracellular neurofibrillary tangles composed of hyperphosphorylated tau protein. Oral RP treatment at a dose of $50 \mathrm{mg} / \mathrm{kg}$ effectively reduced the activity of Ephrin type-A receptor 4 (EphA4) and blocked EphA4-dependent signaling pathways, which negatively regulates synaptic plasticity in the hippocampal neurons, thereby restoring the amyloid precursor protein gene and presenilin 1 gene in transgenic mice (Fu et al., 2014). Furthermore, RP and IRP $(1-100 \mu \mathrm{M})$ exerted neuroprotective effects against $A \beta_{25-35}$-induced neuronal toxicity in PC12 cells by inhibiting intracellular calcium overload and tau protein hyperphosphorylation (Xian et al., 2012). It has been reported that IRP promotes the autophagyinduced clearance of $a$-syn in neuronal cells. IRP $(0.3 \mu \mathrm{M})$ inhibited 1-methyl-4-phenyl pyridinium ${ }^{+}$-induced apoptosis in PC12 cells (Li et al., 2017). In another study, IRP $(6.25-25 \mu \mathrm{M})$ induced autophagy in $\mathrm{N}_{2 \mathrm{a}}$, SH-SY5Y, and PC12 cell lines as well as in primary cortical neurons, via the mTOR pathway, thereby promoting the clearance of various forms of $\alpha$-syn in neuronal cells (Lu et al., 2012). UH alkaloids have been reported to exert anti-depressant effects. Sakakibara et al. (1999) reported that CX (30 mg/kg), IRP (100 mg/kg), and GM (100 mg/kg) markedly decreased locomotor activity through the central dopaminergic system. In another study, IRN (10-40 mg/kg) exerted an antidepressant-like effect in mice in the forced swimming and tail suspension tests by modulating the central monoaminergic neurotransmitter system and inhibiting the activity of monoamine oxidase A (Xian et al., 2017).

HTI and HTE, like other UH alkaloids, have also been demonstrated to possess a protective effect against neuronal death (Kanno et al., 2014). Kanno et al. (2014) evaluated the neuroprotective effects of HTI, HTE, and GM on glutamateinduced cell death with 3-(4,5-dimethylthiazol-2-yl)-2,5diphenyl-tetrazolium bromide (MTT) staining. Cell survival against control cells exposed to glutamate alone was significantly increased with the addition of GM $(3 \mu \mathrm{M})$, HTE $(10 \mu \mathrm{M})$, and HTI $(10 \mu \mathrm{M})$. These components enhanced gene expressions of system $\mathrm{Xc}^{-}$subunits $\mathrm{xCT}$ and $4 \mathrm{~F} 2 \mathrm{hc}$, and also ameliorated the glutamate-induced decrease in glutathione (GSH) levels. These results suggest that the cytoprotective effect of HTI, HTE, and GM may be due to the suppression of GSH reduction by enhancing system $\mathrm{Xc}^{-}$.

GM reportedly exerts multiple effects, such as serotonergic, dopaminergic, and adrenergic neurotransmission, as well as neuroprotection. Using Chinese hamster ovary cells artificially expressing the $5-\mathrm{HT}_{1 \mathrm{~A}}$ receptor, the competitive binding assay and $\left({ }^{3} \mathrm{H}\right) 8$-hydroxy-2-(di-n-propylamino) tetralin binding assay of seven major alkaloids in UH have been investigated. Among the seven alkaloids, only GM exhibited strong binding to $5-\mathrm{HT}_{1 \mathrm{~A}}$ receptors $\left(\mathrm{IC}_{50}: 0.904 \mu \mathrm{M}\right.$ ), acting as a partial agonist (Nishi et al., 2012). The effect of YKS and UH-containing alkaloids on the L-DOPA-derived dopamine production has been investigated using RIN 14B cells that are 5-HT synthesizing cells. YKS and certain alkaloids (CX and GM) inhibited catechol-Omethyltransferase activity $(2000 \mu \mathrm{g} / \mathrm{ml}$ YKS: $83.1 \%, 100 \mathrm{nmol} /$ $\mathrm{ml} \mathrm{CX}: 72.4 \%, 100 \mathrm{nmol} / \mathrm{mL}$ GM: $65.1 \%)$ and significantly increased dopamine production (Ishida et al., 2016). Competitive radioligand and $\left({ }^{35} \mathrm{~S}\right) \mathrm{GTP} \gamma \mathrm{S}$ binding assays have revealed that YKS and GM had specific binding affinity for and antagonist activity against the $\alpha_{2 \mathrm{~A}}$-adrenoceptor $\left(\mathrm{IC}_{50}\right.$ : approximately $300 \mu \mathrm{g} / \mathrm{ml}$ and $3 \mu \mathrm{M}$, respectively), being approximately 10 times stronger than that of hirusutin and hirustein (Nakagawa et al., 2012). Oral administration of $1 \mathrm{~g} / \mathrm{kg}$ YKS improved aggressive behavior and restored social behavior in isolated mice, and oral administration of $150 \mu \mathrm{g} / \mathrm{kg}$ $\mathrm{GM}$, equivalent to $1 \mathrm{~g} / \mathrm{kg}$ YKS, showed similar pharmacological effects (Nishi et al., 2012).

\section{DETECTION AND QUANTIFICATION METHODS}

Measuring UH alkaloids levels is essential for elucidating their pharmacokinetics. Pharmacokinetic studies of UH alkaloids have been progressing along with the development of analytical technologies. To date, various analytical methods for detecting, identifying, and quantifying UH alkaloids have been developed and selectively used according to the purpose of the study (Table 1). For example, high-performance liquid chromatography (HPLC) has been used as a fingerprint analysis to support the quality control of several Japanese Kampo medicines containing UH (Tsuji et al., 2014; Nakatani et al., 2017) and as a quantitative analysis of $\mathrm{UH}$ alkaloids including GM (Hou et al., 2018). Furthermore, liquid chromatography with tandem mass spectrometry (LC-MS/MS) has been utilized to quantify $\mathrm{UH}$ alkaloids concentrations in biological samples, enabling the highly selective and sensitive detection of them. In addition, LC-MS/MS has also been applied to identify and quantify UH alkaloids and their metabolites in plasma, brain, urine, or bile samples from rats and mice after the oral administration of UH-containing crude drug products or pure UH alkaloids (Kushida et al., 2013; Wu et al., 2013; Gai et al., 2014; Zhao et al., 2016b; Tian et al., 2018; Zhang H. et al., 2019; Han et al., 2019; Takiyama et al., 2019; Chen et al., 2020; Matsumoto et al., 2020). In addition, LC-MS/MS has been applied to simultaneously quantify alkaloids in extracts from several Uncaria species for standardization and quality control and to conduct chemical classification of the Uncaria genus (Wang H.-B. et al., 2014). An in vitro autoradiography assay using $\left({ }^{3} \mathrm{H}\right) \mathrm{GM}$ has been performed to determine GM-specific binding sites on brain sections (Mizoguchi et al., 2014). Mass spectrometry imaging (MSI) using matrix-assisted laser desorption ionization (MALDI) (Giordano et al., 2016; Matsumoto et al., 2017) and desorption electrospray ionization (DESI) (Fernandes et al., 2016), which are powerful tools for visualizing the distributions of biological molecules or metabolites in tissue sections, have been applied to obtain images of the distribution of GM in rat brains (Matsumoto et al., 2020).

\section{PHARMACOKINETICS}

Traditional Japanese and Chinese medicines are generally complex products consisting of two or more crude drugs. 
TABLE 1 | Lower limit of quantification and calibration range of UH alkaloids in various analytical methods.

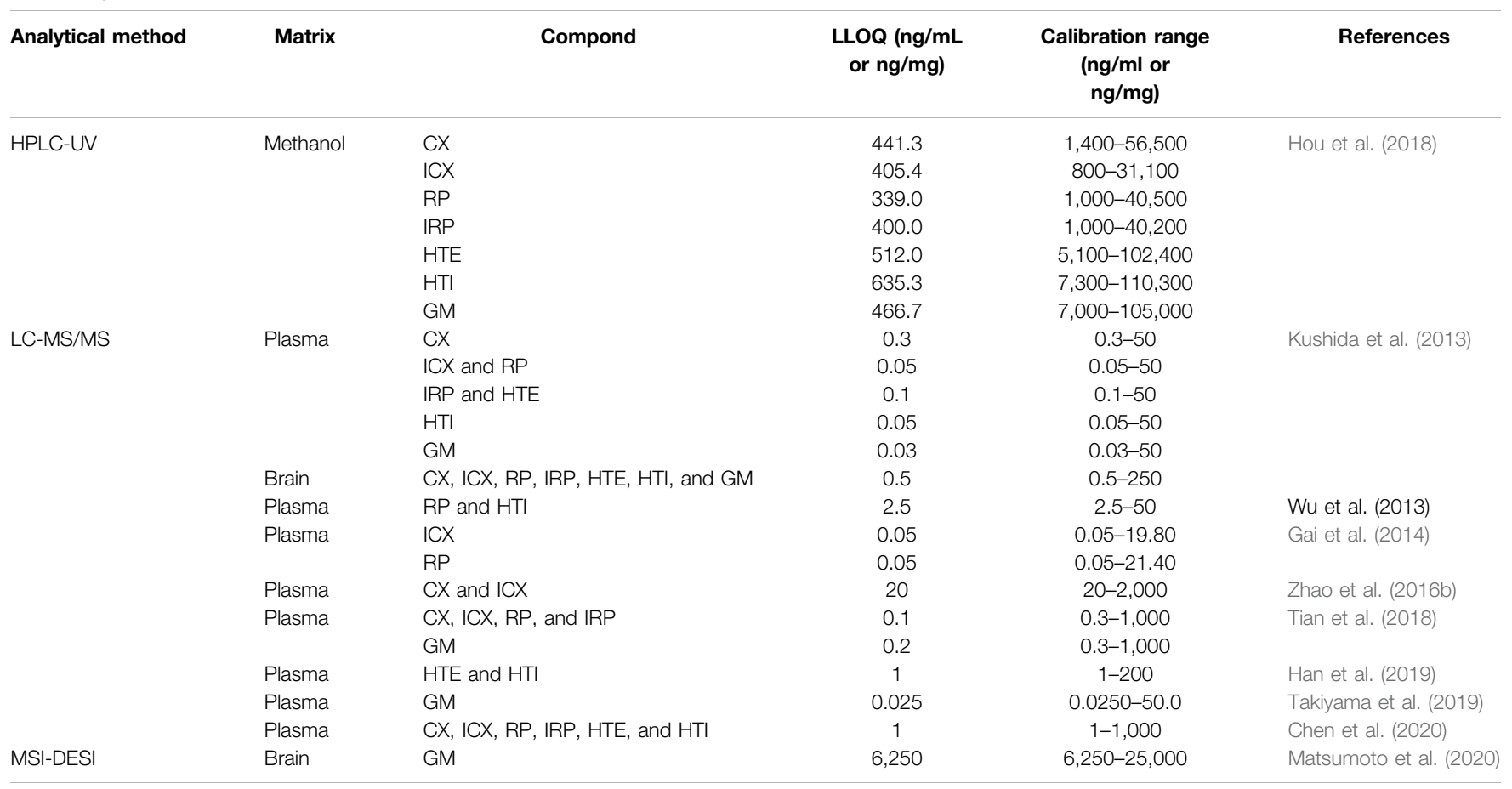

LLOQ: Lower limit of quantification.

Therefore, a single crude drug contains several components with different chemical structures. These structures may affect the properties of the coexisting components through physical and chemical interactions. As a result, the properties of the components of crude drug products might differ significantly from those of the pure components. For this reason, pharmacokinetic studies using crude drug products have limitations. However, because crude drug products are often used in clinical practice rather than individual ingredients, pharmacokinetic studies using crude drug products are useful for studying and understanding the pharmacology of the ingredients under conditions that reflect their clinical use. Conversely, pharmacokinetic studies using individual components reveal the properties of the pure components. Ideally, pharmacokinetic studies of components in crude drugs should be performed using both crude drug mixtures and pure components, as this will provide a better understanding of the properties of the components. Therefore, in this section, we have reviewed the pharmacokinetic properties of $\mathrm{UH}$ alkaloids, focusing on GMs, separately for pharmacokinetic studies using UH-containing crude drug products and pure UH alkaloids.

\section{Absorption}

Recently, the pharmacokinetics and bioavailability of six $\mathrm{UH}$ alkaloids were reported in mouse blood (Chen et al., 2020). In particular, the bioavailabilities of CX, ICX, RP, IRP, HTE, and HTI in mice treated at a dose of $5 \mathrm{mg} / \mathrm{kg}$ orally or $1 \mathrm{mg} / \mathrm{kg}$ intravenously were $27.3,32.7,49.4,29.5,51.0$, and $68.9 \%$, respectively. In another study, the bioavailabilities of HTI and
HTE in rats at the same dose were 4.4 and $8.21 \%$, respectively (Han et al., 2019).

The ability of RP to permeate Caco- 2 cell monolayers has been investigated (Ma et al., 2014). RP permeated the monolayer with velocities of $2.76 \times 10^{-6}-5.57 \times 10^{-6} \mathrm{~cm} / \mathrm{s}$ from the apical side to the basolateral side and $10.68 \times 10^{-6}-15.66 \times 10^{-6} \mathrm{~cm} / \mathrm{s}$ from the basolateral side to the apical side. The ability of RP to permeate cells was increased by verapamil, a P-glycoprotein (P-gp) inhibitor, and rhodamine 123, a P-gp substrate. Furthermore, $\mathrm{RP}$ induced the expression of P-gp in Caco- 2 cells. These results indicate that P-gp may be involved in the low permeability and absorption of RP. In another study, Wang et al. (2017) investigated RP and IRP membrane permeability and efflux by $\mathrm{P}$-gp using in situ single-pass intestinal perfusion with and without verapamil. The intestinal perfusion assay illustrated that IRP possessed higher intestinal permeability than RP, and co-perfusion with verapamil could affect the absorption of RP but not IRP. These results suggest that RP, but not IRP, is a substrate of P-gp.

\section{Exposure to Blood}

Administration of UH-Containing Crude Drug Products

Most pharmacokinetic studies of GM have been performed after the oral administration of crude drug products (Kushida et al., 2013; Matsumoto et al., 2018; Takiyama, et al., 2019) (Table 2). Although the absolute bioavailability of GM has not been verified, many studies revealed that GM in the intestinal lumen following oral administration is certainly absorbed into portal vein blood and transferred to circulating blood. The pharmacokinetics of circulating plasma GM was first reported in male rats orally 
TABLE 2 | Pharmacokinetic studies of UH alkaloids.

\begin{tabular}{lr} 
Drug type & Drug/Route/Animal \\
\hline Crude drug & YKS $(0.25,1,4 \mathrm{~g} / \mathrm{kg})$, oral, male rat
\end{tabular}

product

YKS (1 g/kg), oral, male mice

YKS (1, $4 \mathrm{~g} / \mathrm{kg})$, oral, female rats

YKS (1 g/kg), oral, female rats

YKS (4 g/kg), oral, female rats

YKS (2.5, 5.0, or $7.5 \mathrm{~g} /$ day), oral, male and female humans

YGS $(9.1 \mathrm{~g} / \mathrm{kg})$, oral, rats

Gouteng-Baitouweng ( $25 \mathrm{~g} / \mathrm{kg})$, oral, rats

Pure drug GM $(5 \mathrm{mg} / \mathrm{kg})$, intravenous, rats

CX, ICX, RP, IRP, HTI, and HTE (5 mg/kg), oral, mice

CX, ICX, RP, IRP, HTI, and HTE (1 mg/kg), intravenous, mice

$\mathrm{HTI}$, and HTE, $(5 \mathrm{mg} / \mathrm{kg})$, oral, rats

$\mathrm{HTI}$, and HTE, (1 mg/kg), intravenous, rats

\section{Outcome}

$\mathrm{AUC}_{0-\infty}, C_{\max }, t_{\max }$, and $t_{1 / 2}$ in plasma of $0.0544-0.656 \mathrm{ng} \mathrm{h} / \mathrm{ml}, 0.0759-0.274 \mathrm{ng} /$ $\mathrm{ml}, 0.42-1.0 \mathrm{~h}$, and $1.4 \mathrm{~h}$, respectively, for RP; 0.149-1.59 ng h/ml, 0.160-0.381 ng/ml, 0.50-0.83 h, and $3.4 \mathrm{~h}$, respectively, for HTl; 0.0829-2.08 ng $\mathrm{h} / \mathrm{ml}, 0.125-0.529 \mathrm{ng} / \mathrm{ml}, 0.50-2.0 \mathrm{~h}$, and 1.9-3.6 h, respectively, for HTE; and $0.441-6.79 \mathrm{ng} \mathrm{h} / \mathrm{ml}, 0.261-1.98 \mathrm{ng} / \mathrm{ml}, 0.42-0.67 \mathrm{~h}$, and 1.5-2.0 h, respectively, for GM.

$\mathrm{AUC}_{0-\infty}, C_{\max }, t_{\max }$, and $t_{1 / 2}$ in brain of $2.90 \mathrm{ng} \mathrm{h} / \mathrm{g}, 1.18 \mathrm{ng} / \mathrm{g}, 0.50 \mathrm{~h}$, and $3.4 \mathrm{~h}$ $(4 \mathrm{~g} / \mathrm{kg})$, respectively

GM concentration of about $2.5 \mathrm{ng} / \mathrm{ml}$ at $1 \mathrm{~h}$

GM concentrations in plasma of 2.1 and $9.0 \mathrm{ng} / \mathrm{ml}$, respectively

GM concentrations in brain of 1.6 and $5.9 \mathrm{ng} / \mathrm{ml}$, respectively

$C_{\max }, t_{\max }, t_{1 / 2 \alpha}, t_{1 / 2 \beta}$, and AUC of $12.3 \mathrm{ng} / \mathrm{ml}, 0.508 \mathrm{~h}, 0.194 \mathrm{~h}, 31.1 \mathrm{~h}$, and $29.3 \mathrm{ng}$ $\mathrm{h} / \mathrm{ml}$, respectively

$C_{\text {max }}, t_{\max }, t_{1 / 2}, k_{\mathrm{e}}$, and $\mathrm{AUC}_{0-\infty}$ of $8.46 \mathrm{ng} / \mathrm{ml}, 1.17 \mathrm{~h}, 2.14 \mathrm{~h}, 0.33 \mathrm{~h}^{-1}$, and $33.7 \mathrm{ng}$ $\mathrm{h} / \mathrm{ml}$, respectively

$C_{\max }, \mathrm{AUC}_{0-\text { last }}, t_{1 / 2}$, and $t_{\max }$ of $0.650-1.98 \mathrm{ng} / \mathrm{ml}, 1.18-4.81 \mathrm{ng} \mathrm{h} / \mathrm{ml}, 1.72-1.95 \mathrm{~h}$, and $0.500 \mathrm{~h}$, respectively, for GM and of $0.138-0.450 \mathrm{ng} / \mathrm{ml}, 0.277-1.50 \mathrm{ng} \mathrm{h} / \mathrm{ml}$, 2.47-3.03 $\mathrm{h}$, and 0.975-1.00 h, respectively, for HTE.

AUC, $C_{\max }, t_{\max }, t_{1 / 2}, M R T, C L / F$, and V/F were $64.70 \mathrm{ng} \mathrm{h} / \mathrm{ml}, 9.43 \mathrm{ng} / \mathrm{ml}, 4.76 \mathrm{~h}$, $8.68 \mathrm{~h}, 7.25 \mathrm{~h}, 2.72 \mathrm{~L} \mathrm{~h} / \mathrm{kg}$, and 39.79 , respectively, for $\mathrm{RP}$ and $41.02 \mathrm{ng} \mathrm{h} / \mathrm{ml}$, $3.89 \mathrm{ng} / \mathrm{ml}, 1.79 \mathrm{~h}, 9.11 \mathrm{~h}, 7.82 \mathrm{~h}, 6.65 \mathrm{~L} \mathrm{~h} / \mathrm{kg}$, and $83.73 \mathrm{~L} / \mathrm{kg}$, respectively, for ICX.

AUCs of RP, IRP, CX, ICX, and GM in portal vein plasma were 2083.2, 647.0, 767.3, 2,237.4, and $41.1 \mathrm{ng} \mathrm{h/ml}$, respectively.

AUCs of RP, IRP, CX, and ICX in systemic plasma were 349.6, 51.0, 35.1, and $265.8 \mathrm{ng} \mathrm{h} / \mathrm{ml}$, respectively

One-compartment model with $k_{\mathrm{e}}$ of $0.4 \mathrm{~h}^{-1}$, a $t_{1 / 2}$ of $1.8 \mathrm{~h}$, a $\mathrm{CL}_{\text {total }}$ of $1.7 \mathrm{~L} / \mathrm{h} / \mathrm{kg}$, and $\mathrm{Vd}$ of $4.4 \mathrm{~L} / \mathrm{kg}$

AUCs of CX, ICX, RP, IRP, HTI, and HTE were 260.9, 293.1, 416.7, 209.2, 899.7, and $511.3 \mathrm{ng} \mathrm{h} / \mathrm{ml}$, respectively, $C_{\max }$ were $374.8,373.2,508.0,305.3,524.5$, and $360.8 \mathrm{ng} / \mathrm{ml}$, respectively, MRT were $0.9,1.6,1.7,1.2,1.8$, and $1.6 \mathrm{~h}$; respectively, t1/2 were 0.7, 1.6, 4.4 2.5, 2.0, and 2.4 h, respectively; CL/F were 20.2, 18.2, 11.6, 24.7, 5.6, and $9.8 \mathrm{~L} / \mathrm{h} / \mathrm{kg}$, respectively; and $\mathrm{V} / \mathrm{F}$ were 19.3, 45.7, 60.1, 84.5, 16.8, and $36.1 \mathrm{~L} / \mathrm{kg}$, respectively

AUCs of CX, ICX, RP, IRP, HTI, and HTE were 191.4, 179.2, 168.6, 142.0, 261.3, and $200.7 \mathrm{ng} \mathrm{h} / \mathrm{ml}$, respectively, $C_{\max }$ were $230.7,221.2,199.3,184.6,222.6$, and $188.4 \mathrm{ng} / \mathrm{ml}$, respectively, MRT were $0.2,0.3,0.5,0.2,0.9$, and $0.9 \mathrm{~h}$; respectively, $\mathrm{t} 1 / 2$ were $0.5,3.2,2.2,0.6,1.1$, and $2.2 \mathrm{~h}$, respectively; CL were 6.2, 6.1, 6.2, 7.4, 4.4, and $5.2 \mathrm{~L} / \mathrm{h} / \mathrm{kg}$, respectively; and $\mathrm{V}$ were $4.4,28.7,20.0,6.8,8.3$, and $15.9 \mathrm{~L} / \mathrm{kg}$, respectively

AUC of $\mathrm{HTI}$ and HTE were 70.8 and 70.3, respectively, Cmax were 21.9 and $17.8 \mathrm{ng} / \mathrm{ml}$, MRT were 3.6 and $4.4 \mathrm{~h}$, respectively, t1/2 were 1.8 and $3.5 \mathrm{~h}$, respectively, CL/F were 73.2 and $74.0 \mathrm{~L} / \mathrm{h} / \mathrm{kg}$, respectively, and $\mathrm{V} / \mathrm{F}$ were 189.4 and $359.0 \mathrm{~L} / \mathrm{kg}$, respectively

AUC of HTI and HTE were 322.9 and 173.3, respectively, $C_{\max }$ were 97.9 and $72.5 \mathrm{ng} / \mathrm{ml}$, MRT were 5.0 and $3.1 \mathrm{~h}$, respectively, t1/2 were 2.6 and $4.1 \mathrm{~h}$, respectively, $\mathrm{CL}$ were 3.1 and $5.7 \mathrm{~L} / \mathrm{h} / \mathrm{kg}$, respectively, and $\mathrm{V}$ were 11.9 and $34.9 \mathrm{~L} / \mathrm{kg}$, respectively

\section{References}

Kushida et al. (2013) 
administration of YKS $(1.0 \mathrm{~g} / \mathrm{kg})$, and then the compound immediately disappeared $(t 1 / 2 \alpha=0.194 \mathrm{~h}, t 1 / 2 \beta=31.1 \mathrm{~h})$ over $24 \mathrm{~h}$. AUC was $29.3 \mathrm{ng} \mathrm{h} / \mathrm{mL}$. When $C_{\max }$ and AUC were compared between female (Takiyama et al., 2019) and male rats (Kushida et al., 2013) administered the same dose of YKS (1 g/kg), the plasma GM concentration was much higher in female rats than in male rats. These findings suggested gender differences in plasma GM concentrations in rats. Indeed, we recently demonstrated that a significant gender difference in the rat plasma pharmacokinetics of GM by revealing that $C_{\max }$ and AUC of plasma GM in female rats were approximately 4-fold higher than those in male rats after oral administration of the same dose of YKS (Kushida et al., 2021). The causes of the gender differences in rat plasma GM pharmacokinetics are discussed in the "Mmetabolism by Cytochrome P450 in the Liver" section.

In humans, a randomized crossover study examined the pharmacokinetics of several active components including GM using 21 healthy Japanese volunteers who orally received YKS $\left(2.5,5.0\right.$, or $7.5 \mathrm{~g} /$ day). $C_{\max }$ of GM increased in a dose-dependent manner over the range of $0.650-1.98 \mathrm{ng} / \mathrm{ml}$ with a similar $t_{\max }$ $(0.500 \mathrm{~h})$ across the groups. $t_{1 / 2}$ was similar among the groups, ranging from 1.72 to $1.95 \mathrm{~h}$. Consequently, AUC increased in a dose-dependent manner, ranging from 1.18 to $4.81 \mathrm{ng} \mathrm{h} / \mathrm{mL}$ (Kitagawa et al., 2015). The rapid rise and disappearance of plasma GM after oral YKS administration in humans were similar to those in rodents, but unlike rats, no gender differences in GM plasma pharmacokinetics were observed. This result suggests that humans probably have no gender differences in GM metabolism, although more clinical evidence needs to be accumulated in the future.

Similar to the findings for GM, the blood concentrations of other UH alkaloids during the administration of crude drug products have also been investigated. We have studied the pharmacokinetics of $\mathrm{UH}$ alkaloids in plasma after oral YKS administration $(0.25,1$, and $4 \mathrm{~g} / \mathrm{kg}$ ) in male rats (Kushida et al., 2013). In addition to GM, RP, HTI, and HTE were detected in rat plasma, whereas CX, ICX, and IRP were not detected. RP, HTI, and HTE appeared rapidly in the circulating blood and disappeared rapidly, and the plasma concentration-time curves were similar to those of GM. AUC, $C \max , \quad t \max$, and $t 1 / 2$ were $0.0544-0.656 \mathrm{ng} \mathrm{h} / \mathrm{ml}$, $0.0759-0.274 \mathrm{ng} / \mathrm{ml}, 0.42-1.0 \mathrm{~h}$, and $1.4 \mathrm{~h}$, respectively, for RP; $0.149-1.59 \mathrm{ng} \mathrm{h} / \mathrm{ml}, 0.160-0.381 \mathrm{ng} / \mathrm{ml}, 0.50-0.83 \mathrm{~h}$, and $3.4 \mathrm{~h}$, respectively, for HTI; and $0.0829-2.08 \mathrm{ng} \mathrm{h} / \mathrm{ml}, 0.125-0.529 \mathrm{ng} /$ $\mathrm{ml}, 0.50-2.0 \mathrm{~h}$, and 1.9-3.6 h, respectively, for HTE. Gai et al. (2014) measured ICX and RP levels in rat plasma after the oral administration of $9.1 \mathrm{~g} / \mathrm{kg}$ YGS, which has the same composition as YKS, via targeted analysis using LC-MS/MS and calculated their pharmacokinetic parameters. AUC, $C_{\max }, t_{\max }, t_{1 / 2}$, the mean residence time (MRT), clearance rate/bioavailability (CL/ F), and the apparent distribution volume/bioavailability (V/F) were $64.70 \mathrm{ng} \mathrm{h} / \mathrm{ml}, 9.43 \mathrm{ng} / \mathrm{ml}, 4.76 \mathrm{~h}, 8.68 \mathrm{~h}, 7.25 \mathrm{~h}, 2.72 \mathrm{~L} \mathrm{~h} / \mathrm{kg}$, and 39.79, respectively, for $\mathrm{RP}$ and $41.02 \mathrm{ng} \mathrm{h} / \mathrm{ml}, 3.89 \mathrm{ng} / \mathrm{ml}$, $1.79 \mathrm{~h}, 9.11 \mathrm{~h}, 7.82 \mathrm{~h}, 6.65 \mathrm{~L} \mathrm{~h} / \mathrm{kg}$, and $83.73 \mathrm{~L} / \mathrm{kg}$, respectively, for ICX. Regarding other UH-containing crude drug products, the pharmacokinetics of CX, ICX, RP, IRP, and GM in systemic and portal vein plasma following the oral administration of Gouteng-
Baitouweng (25 g/kg) to rats was reported (Tian et al., 2018). All five UH alkaloids were detected in portal vein plasma, whereas all $\mathrm{UH}$ alkaloids except GM were detected in systemic plasma. The AUCs of RP, IRP, CX, ICX, and GM in portal vein plasma were 2083.2, 647.0, 767.3, 2,237.4, and $41.1 \mathrm{ng} \mathrm{h} / \mathrm{ml}$, respectively. Furthermore, those of RP, IRP, CX, and ICX in systemic plasma were $349.6,51.0,35.1$, and $265.8 \mathrm{ng} \mathrm{h} / \mathrm{ml}$, respectively. The AUCs were much lower in systemic plasma than in portal vein plasma. These results suggest that $\mathrm{UH}$ alkaloids are metabolized in the liver. In addition, GM was not detected in systemic plasma. The GM concentration in portal vein plasma is much lower than that of other alkaloids, suggesting that the GM content in Gouteng-Baitouweng is low. It has been reported that the contents of indole and oxindole alkaloids in UH depend on its botanical origin and hook size (Hou et al., 2018).

\section{Administration of Pure UH Alkaloids}

As described previously, the pharmacokinetics of GM following the oral administration of YKS has been well studied, whereas information regarding its pharmacokinetics following the administration of GM alone is limited (Table 2). Matsumoto et al. (2020) reported the plasma concentrations vs. time profile following the intravenous injection of GM and found that the profile well fitted to a one-compartment model, and the pharmacokinetic parameters obtained in their model analysis were as follows: elimination rate constant of $0.4 \mathrm{~h}-1, t 1 / 2$ of $1.8 \mathrm{~h}$, total $\mathrm{CL}$ of $1.7 \mathrm{~L} / \mathrm{h} / \mathrm{kg}$, and $\mathrm{V}$ of $4.4 \mathrm{~L} / \mathrm{kg}$.

Conversely, several pharmacokinetic studies using pure $\mathrm{UH}$ alkaloids (excluding GM) have been reported (Han et al., 2019; Chen et al., 2020). Chen et al. (2020) determined the pharmacokinetic parameters of six indole and oxindole alkaloids after oral and intravenous administrations at doses of 5 and $1 \mathrm{mg} / \mathrm{kg}$, respectively, in mice. In the case of oral administration, MRTs of CX, ICX, RP, IRP, HTI, and HTE were $0.9,1.6,1.7,1.2,1.8$, and $1.6 \mathrm{~h}$; respectively, the $t_{1 / 2}$ times were $0.7,1.6,4.4,2.5,2.0$, and $2.4 \mathrm{~h}$, respectively; the $\mathrm{CL} / \mathrm{F}$ values were $20.2,18.2,11.6,24.7,5.6$, and $9.8 \mathrm{~L} / \mathrm{h} / \mathrm{kg}$, respectively; and the $\mathrm{V} / \mathrm{F}$ values were $19.3,45.7,60.1,84.5,16.8$, and $36.1 \mathrm{~L} / \mathrm{kg}$, respectively. The pharmacokinetic parameters of HTI and HTE in rats following oral and intravenous administrations were calculated by Han et al. (2019). MRT (3.6 and $4.4 \mathrm{~h}$ ) and $t_{1 / 2}$ (1.8 and $3.5 \mathrm{~h}$ ) of HTI and HTE in rats after oral administration were not significantly different from those in mice, but CL/F (73.2 and $74.0 \mathrm{~L} / \mathrm{h} / \mathrm{kg})$ and $\mathrm{V} / \mathrm{F}(189.4$ and $359.0 \mathrm{~L} / \mathrm{kg})$ were approximately 10-fold larger. CL and V of HTI and HTE in rats after intravenous administration were almost the same as those in mice; specifically, the CL values of HTI and HTE were 4.4 and $5.2 \mathrm{~L} / \mathrm{h} / \mathrm{kg}$, respectively, in mice and 3.1 and $5.7 \mathrm{~L} / \mathrm{h} / \mathrm{kg}$, respectively, in rats. Similarly, the V values of HTI and HTE were 8.3 and $15.9 \mathrm{~L} / \mathrm{kg}$, respectively, in mice and 11.9 and $34.9 \mathrm{~L} / \mathrm{kg}$, respectively, in rats.

\section{Metabolism}

\section{Liver First-Pass Effect}

When an herbal medicine or crude drug product is orally administered, its constituents are first absorbed into the portal vein blood via intestinal absorption and subjected to a first-pass 
TABLE 3 | Metabolism studies of UH alkaloids.

\begin{tabular}{|c|c|c|c|c|}
\hline Study type & Model/Subject & Drug/Route & Outcome & References \\
\hline \multirow[t]{2}{*}{ Liver first pass } & Male rats & $\begin{array}{l}\text { Gouteng-Baitouweng } \\
(25 \mathrm{~g} / \mathrm{kg}) \text {, Oral }\end{array}$ & $\begin{array}{l}\text { GM was detected in portal vein plasma, but not in systemic } \\
\text { plasma }\end{array}$ & Tian et al. (2018) \\
\hline & Male rats & $\begin{array}{l}\text { Tianma-Gouteng granule }(2.5 \\
\text { and } 5 \mathrm{~g} / \mathrm{kg}) \text {, Oral }\end{array}$ & $\begin{array}{l}\text { GM and acidic or reduced/demethylated metabolites of GM } \\
\text { were detected in plasma }\end{array}$ & $\begin{array}{l}\text { Zhang et al. } \\
\text { (2019b) }\end{array}$ \\
\hline \multirow[t]{9}{*}{$\begin{array}{l}\text { In vitro } \\
\text { metabolism }\end{array}$} & Rat and human liver microsomes & $\mathrm{GM}$ & $\begin{array}{l}\text { GM was metabolized into at least } 13 \text { metabolites including } \\
\text { hydroxylated, dehydrogenated, hydroxylated/ } \\
\text { dehydrogenated, demethylated, and hydrated forms }\end{array}$ & $\begin{array}{l}\text { Kushida et al. } \\
\text { (2015) }\end{array}$ \\
\hline & $\begin{array}{l}\text { Human liver microsomes and } \\
\text { recombinant human CYPs, RAF } \\
\text { method }\end{array}$ & GM & $\begin{array}{l}\text { GM was metabolized by CYP3A4 (61.3\%), CYP2C19 } \\
(23.5 \%) \text {, and CYP2D6 (15.2\%) }\end{array}$ & $\begin{array}{l}\text { Matsumoto et al. } \\
\text { (2016) }\end{array}$ \\
\hline & $\begin{array}{l}\text { Rat liver S9 and microsomes, } \\
\text { recombinant rat CYPs }\end{array}$ & GM & $\begin{array}{l}\text { CYP1A1, CYP2C6, CYP2C11, CYP2D1, and CYP3A2 were } \\
\text { involved in GM metabolism }\end{array}$ & $\begin{array}{l}\text { Kushida et al. } \\
\text { (2021) }\end{array}$ \\
\hline & Rat liver microsomes & $\mathrm{IRP}$ & $\begin{array}{l}25 \text { metabolites produced by oxidation, hydrolysis, reduction, } \\
\text { demethylation, hydroxylation, and dehydrogenation }\end{array}$ & $\begin{array}{l}\text { Wang et al. } \\
(2016 a)\end{array}$ \\
\hline & Rat liver microsomes & $\mathrm{RP}$ and IRP & $\begin{array}{l}\text { Hydroxylation at the A-ring was the major metabolic pathway } \\
\text { for RP } \\
\text { Oxidation at the C-ring was the major metabolic pathway } \\
\text { for IRP }\end{array}$ & $\begin{array}{l}\text { Wang et al. } \\
(2017)\end{array}$ \\
\hline & recombinant rat CYPs & $\mathrm{ICX}$ & $\begin{array}{l}\text { CYP2C19 and CYP2D6 were involved in the production of } \\
\text { 18,19-dehydrocorynoxinic acid, and CYP3A4 was involved in } \\
\text { the production of 5-Oxo ICX. }\end{array}$ & $\begin{array}{l}\text { Zhao et al. } \\
(2016 b)\end{array}$ \\
\hline & $\begin{array}{l}\text { Rat liver microsomes, specific } \\
\text { inhibitors }\end{array}$ & $\operatorname{IRP}$ & $\begin{array}{l}\text { CYP1A1/2, CYP2C, and CYP2D, but not CYP3A, are } \\
\text { involved in the 10- and 11-hydroxylation of IRP. }\end{array}$ & $\begin{array}{l}\text { Wang et al. } \\
\text { (2010a) }\end{array}$ \\
\hline & $\begin{array}{l}\text { Rat liver microsomes, specific } \\
\text { inhibitors }\end{array}$ & $\mathrm{RP}$ & $\begin{array}{l}\text { CYP1A1/2, CYP2C, and CYP2D, but not CYP3A, are } \\
\text { involved in the 10- and 11-hydroxylation of RP }\end{array}$ & $\begin{array}{l}\text { Wang et al. } \\
\text { (2010b) }\end{array}$ \\
\hline & $\begin{array}{l}\text { Rat liver microsomes, specific } \\
\text { inhibitors }\end{array}$ & $\mathrm{HTI}$ and HTE & $\begin{array}{l}\text { CYP2C is involved in the } 10 \text { - and 11-hydroxylation of } \mathrm{HTI} \\
\text { and THE }\end{array}$ & $\begin{array}{l}\text { Nakazawa et al. } \\
(2006)\end{array}$ \\
\hline \multirow[t]{9}{*}{$\begin{array}{l}\text { In vivo } \\
\text { metabolism }\end{array}$} & Male rats & $\begin{array}{l}\text { Tianma-Gouteng Yin granule } \\
(2.5 \text { and } 5 \mathrm{~g} / \mathrm{kg}) \text {, Oral }\end{array}$ & $\begin{array}{l}\text { GM and acidic or reduced/demethylated metabolites of GM } \\
\text { were detected in plasma. } \\
\text { Corynoxeinic acid, isocorynoxeinic acid, rhynchophyllinic } \\
\text { acid, isorhynchophyllinic acid, and hirsuteinic acid, and their } \\
22-0-\beta \text {-glucuronides were detected in plasma and bile, } \\
\text { respectively }\end{array}$ & $\begin{array}{l}\text { Zhang et al. } \\
\text { (2019b) }\end{array}$ \\
\hline & Rats & CX $(0.105 \mathrm{mM} / \mathrm{kg})$, oral & $\begin{array}{l}\text { 10- and 11-Hydroxy CX have been isolated from urine and } \\
\text { faces, and 10-hydroxy CX 10-O- } \beta \text {-D-glucuronide and } 11- \\
\text { hydroxy } C X 11-O-\beta-D \text {-glucuronide were isolated from the bile }\end{array}$ & $\begin{array}{l}\text { Wang et al. } \\
(2014 b)\end{array}$ \\
\hline & Rats & ICX (40 mg/k), oral & $\begin{array}{l}\text { 10- and 11-Hydroxy ICX, 10-hydroxy ICX 10-O- } \beta \text {-D- } \\
\text { glucuronide and } 11 \text {-hydroxy ICX 11-O- } \beta \text {-D-glucuronide were } \\
\text { isolated from the bile }\end{array}$ & Chen et al. (2014) \\
\hline & Rats & ICX (40 mg/kg), oral & $\begin{array}{l}\text { 11-hydroxy ICX, 5-oxoisocorynoxeinic acid-22-O- } \beta \text {-D- } \\
\text { glucuronide, 10-hydroxy ICX, 17-O-demethyl-16,17-dihydro- } \\
\text { 5-oxo ICX, 5-oxoisocorynoxeinic acid, 21-hydroxy-5-oxo } \\
\text { ICX, oxireno[18, 19]-5-oxo ICX, 18,19-dehydrocorynoxinic } \\
\text { acid, 18,19-dehydrocorynoxinic acid B, CX, ICX-N-oxide, } \\
\text { and CX-N-oxide were detected in urine }\end{array}$ & Qi et al. (2015) \\
\hline & Rats & ICX (40 mg/kg), oral & $\begin{array}{l}\text { 18, 33, and } 18 \text { metabolites produced by hydrolysis, oxidation, } \\
\text { isomerization, demethylation, epoxidation, reduction, } \\
\text { glucuronidation, hydroxylation, and } \mathrm{N} \text {-oxidation were } \\
\text { detected in plasma, urine, and bile, respectively }\end{array}$ & $\begin{array}{l}\text { Zhao et al. } \\
\text { (2016a) }\end{array}$ \\
\hline & Rats & ICX (40 mg/kg), oral & $\begin{array}{l}\text { 8,19-dehydrocorynoxinic acid, 18,19-dehydrocorynoxinic } \\
\text { acid B, 5-oxoisocorynoxeinic acid-22-O-glucuronide, 17-O- } \\
\text { demethyl-16,17-dihydro-5-oxo ICX, 5-oxoisocorynoxeinic } \\
\text { acid, and 5-oxoisorhynchophyllic acid were identified in } \\
\text { plasma }\end{array}$ & $\begin{array}{l}\text { Zhao et al. } \\
\text { (2016b) }\end{array}$ \\
\hline & Rats & IRP (20 mg/kg), oral & $\begin{array}{l}\text { 10- and 11-Hydroxy IRP were isolated from urine and feces. } \\
10-\text { and } 11 \text {-Hydroxy IRP- } \beta \text {-O-glucuronides were isolated } \\
\text { from bile }\end{array}$ & $\begin{array}{l}\text { Wang et al. } \\
(2010 a)\end{array}$ \\
\hline & Rats & $\mathrm{RP}(37.5 \mathrm{mg} / \mathrm{kg})$, oral & $\begin{array}{l}10-\text { and } 11 \text {-Hydroxy RP were isolated from urine and feces. } \\
10-\text { and } 11 \text {-Hydroxy RP- } \beta \text {-O-glucuronides were isolated from } \\
\text { bile }\end{array}$ & $\begin{array}{l}\text { Wang et al. } \\
\text { (2010b) }\end{array}$ \\
\hline & Rats & IRP (20 mg/kg), oral & $\begin{array}{l}47,21 \text {, and } 18 \text { metabolites of IRP were identified in rat urine, } \\
\text { plasma, and liver, respectively }\end{array}$ & $\begin{array}{l}\text { Wang et al. } \\
(2016 a)\end{array}$ \\
\hline
\end{tabular}

(Continued on following page) 
TABLE 3 | (Continued) Metabolism studies of UH alkaloids.

\begin{tabular}{|c|c|c|c|c|}
\hline Study type & Model/Subject & Drug/Route & Outcome & References \\
\hline & Rats & HTI (20 mg/kg), oral & $\begin{array}{l}67 \text { metabolites by hydroxylation, dehydrogenation, oxidation, } \\
\mathrm{N} \text {-oxidation, hydrolysis, reduction, and glucuronide } \\
\text { conjugation }\end{array}$ & $\begin{array}{l}\text { Wang et al. } \\
\text { (2016b) }\end{array}$ \\
\hline & Rats & $\mathrm{HTI}$ and HTE (50 mg/kg), oral & $\begin{array}{l}\text { 11-hydroxy HTE-11-O- } \beta \text {-D-glucuronide, 11-hydroxy HTE, } \\
11 \text {-hydroxy HTI-11-O- } \beta \text {-D-glucuronide, and 11-hydroxy HTI } \\
\text { from the bile and urine }\end{array}$ & $\begin{array}{l}\text { Nakazawa et al. } \\
\text { (2006) }\end{array}$ \\
\hline
\end{tabular}

effect in the liver. Subsequently, the compounds enter systemic blood, which carries them to the target tissue.

Table 3 showed detailed information of the metabolism studies of UH alkaloids. Tian et al. (2018) performed the simultaneous determination of five Uncaria alkaloids [an indole alkaloid GM and four oxindole alkaloids (RP, IRP, CX, and ICX)] in portal vein plasma, liver, systemic plasma, and brain samples after the oral administration of Gouteng-Baitouweng in male rats. All five alkaloids were detected in portal vein plasma and the liver. However, GM was not detected in systemic plasma. Although the four other alkaloids were detected in systemic plasma, their AUCs were significantly lower than those in portal vein plasma, i.e., plasma before hepatic metabolism. These results suggest that the liver first-pass effect plays a critical role in the pharmacokinetics of Uncaria alkaloids including GM.

Zhang H. et al. (2019) identified the absorbed Uncaria alkaloids and their metabolites in the suborbital vein plasma and bile of male rats orally administered Tianma-Gouteng granules. Indole alkaloids (GM, HTE, and HTI) and oxindole alkaloids (RP, IRP, CX, and ICX) were detected in plasma along with their acidic or reduced/demethylated metabolites. Concerning the oxindole alkaloids, their glucuronidated metabolites were additionally detected in plasma and bile, suggesting that oxindole alkaloids, but not indole alkaloids, are excreted in bile as glucuronidated metabolites. However, the possibility of the biliary excretion of indole alkaloids cannot be dismissed by this study alone because the content of indole alkaloids might be low in Tianma-Gouteng granules. In addition to this finding, Nakazawa et al. (2006) detected 11hydroxyhirsuteine-11-O- $\beta$-D-glucuronide or 11hydroxyhirsutine-11-O- $\beta$-D- glucuronide was detected in the bile and urine of rats orally administered a high dose $(50 \mathrm{mg} / \mathrm{kg})$ of the GM-like indole alkaloid HTE or HTI, respectively. The study suggested that the glucuronides were predominantly excreted into bile rather than urine (Nakazawa et al., 2006). Therefore, the biliary excretion of GM should be examined in more detail in the future.

\section{In Vitro Metabolites}

GM metabolites were identified or estimated from fragment ion patterns obtained by LC-MS/MS analysis after incubating GM with rat and human liver microsomes, and their molecular structures were proposed based on the characteristics of their precursor and product ions, as well as their chromatographic retention times (Kushida et al., 2015). At least 13 GM metabolites were found in the incubation sample compared to the blank sample. The 13 confirmed metabolites were 2 demethylation (M1-1 and M1-2), 1 dehydrogenation (M2-1), 3 oxidation/ dehydrogenation (M3-1, M3-2, and M3-3), 3 oxidation (M4-1, M4-2, and M4-3), 2 water adduction (M5-1 and M5-2), 1 didemethylation (M6-1), and 1 water adduction/oxidation metabolites (M7-1). No difference could be observed between rat and human liver microsome-produced versions of these metabolites.

In addition to GM, the metabolites of RP and IRP have also been investigated via in vitro metabolism studies using liver microsomes (Wang J. et al., 2016; Wang et al., 2018). After rat liver microsomes were incubated with RP or IRP, five RP metabolites and three IRP metabolites were found to react with the A- and C-rings. Among metabolic pathways including oxidation, hydroxylation, N-oxidation, and dehydrogenation, hydroxylation at the A-ring was the major metabolic pathway for RP, whereas oxidation at the C-ring was the major metabolic pathway for IRP (Wang et al., 2018). Furthermore, Wang J. et al. (2016) also found that after incubation of rat liver microsomes with IRP, 25 metabolites were produced through six metabolic pathways: oxidation, hydrolysis, reduction, demethylation, hydroxylation, and dehydrogenation. Of these, hydrolysis, hydroxylation, and oxidation are the main metabolic pathways of IRP.

\section{In Vivo Metabolites}

To date, several GM metabolites have been identified via in vivo studies. When Tianma-Gouteng Yin granules were administered orally to rats at doses of 2.5 and $5 \mathrm{~g} / \mathrm{kg}$, demethylated GM was identified in plasma and bile (Zhang H. et al., 2019). Furthermore, 18-hydroxy-GM was detected in 8-h urine samples from mice orally administered with YGS (Gai et al., 2014). This GM metabolite is potentially predicted to be M4-3. The hydroxylated GM metabolites were also detected by DESI-MSI in the brain tissue from intravenously GM-injected rats (Matsumoto et al., 2020). Furthermore, studies using the RAF method suggested that the production of hydroxylated GM metabolites in humans was the main reaction (Matsumoto et al., 2016). From these results, the main GM metabolite form is potentially inferred to be hydroxylated. As described in the "Liver first-pass effect" section, hydroxylated GM metabolites are thought to be subsequently excreted in the urine as glucuronide conjugates. However, few GM metabolite-related studies have been performed so far in biological samples, such as plasma, urine, and bile. In order to fully understand the pharmacological activity and safety of GM, it would be indispensable to identify its metabolites. 
Contrarily, several studies investigated the metabolites of other $\mathrm{UH}$ alkaloids. Corynoxeinic acid, isocorynoxeinic acid, rhynchophyllinic acid, isorhynchophyllinic acid, and hirsuteinic acid (demethylated metabolites), as well as their $22-O-\beta$-glucuronides, have been detected in plasma and bile after the oral administration of Tianma-Gouteng Yin granules (2.5 and $5 \mathrm{~g} / \mathrm{kg}$ ) to rats (Zhang $\mathrm{H}$. et al., 2019).

10- and 11-Hydroxy CX have been isolated from urine and faces, and 10-hydroxy CX 10-O- $\beta$-D-glucuronide and 11hydroxy CX 11-O- $\beta$-D-glucuronide were isolated from the bile of rats orally administered pure CX (Wang W. et al., 2014). Concerning ICX, the epimer of CX, 10- and 11-hydroxy ICX and their 10- and 11- $\beta$-O-glucuronides have been isolated from the excreta and bile of rats who were administered pure ICX, similarly as observed for CX (Chen et al., 2014). In another study, 11-hydroxy ICX, 5-oxoisocorynoxeinic acid-22-O- $\beta$-Dglucuronide, 10-hydroxy ICX, 17-O-demethyl-16,17-dihydro-5oxo ICX, 5-oxoisocorynoxeinic acid, 21-hydroxy-5-oxo ICX, oxireno[18, 19]-5-oxo ICX, 18,19-dehydrocorynoxinic acid, 18,19-dehydrocorynoxinic acid B, CX, ICX-N-oxide, and CX$\mathrm{N}$-oxide were detected in rat urine following oral ICX administration (Qi et al., 2015). After oral ICX administration, 18,33 , and 18 metabolites produced by hydrolysis, oxidation, isomerization, demethylation, epoxidation, reduction, glucuronidation, hydroxylation, and $\mathrm{N}$-oxidation were detected in plasma, urine, and bile, respectively (Zhao et al., 2016a), and 18,19-dehydrocorynoxinic acid, 18,19-dehydrocorynoxinic acid $\mathrm{B}, 5$-oxoisocorynoxeinic acid-22-O-glucuronide, 17-O-demethyl16,17-dihydro-5-oxo ICX, 5-oxoisocorynoxeinic acid, and 5oxoisorhynchophyllic acid were the main metabolites of ICX in plasma (Zhao et al., 2016b).

As 10- and 11-Hydroxy RP and IRP have been isolated from urine and feces, and their 10 - and 11- $\beta$-O-glucuronides were isolated from bile in in vivo studies using rats administered pure RP or IRP (Wang et al., 2010a; Wang et al., 2010b). In another study, 47, 21, and 18 metabolites were identified in rat urine, plasma, and liver, respectively, after the oral administration of pure IRP. Seven metabolic pathways, namely dehydrogenation, oxidation, hydrolysis, reduction, demethylation, hydroxylation, and glucuronidation were involved in the metabolism. Among them, dehydrogenation, hydrolysis, hydroxylation, and oxidation were considered the main metabolic pathways according to the in vivo and in vitro metabolic profiles (Wang J. et al., 2016).

Nakazawa et al. (2006) isolated 11-hydroxy HTE-11-O- $\beta$-Dglucuronide, 11-hydroxy HTE, 11-hydroxy HTI-11-O- $\beta$-Dglucuronide, and 11-hydroxy HTI from the bile and urine of rats treated with HTE and HTI. In addition, Wang et al. (2016b) found that after oral administration to rats, HTI was converted to 67 metabolites by hydroxylation, dehydrogenation, oxidation, $\mathrm{N}$-oxidation, hydrolysis, reduction, and glucuronide conjugation.

\section{Metabolism by CYPs in the Liver}

As mentioned in the previous section, GM is metabolized into at least 13 metabolites including hydroxylated, dehydrogenated, hydroxylated/dehydrogenated, demethylated, and hydrated forms, as described by an in vitro study using rat and human liver microsomes. A subsequent study identified CYP isoforms predominantly involved in GM metabolism in human liver microsomes. The relative contribution ratio of each CYP isoform was estimated using the relative activity factor method, revealing that the majority of GM (61.3\%) is dehydrogenated and/ or hydroxylated by CYP3A4, 23.5\% is demethylated or hydrated by CYP2C19, and the remaining $15.2 \%$ is demethylated or hydroxylated by CYP2D6 (Matsumoto et al., 2016).

In the "Exposure to Blood" section, we described gender differences of GM pharmacokinetics in rats but not in humans. Generally, pharmacological and pharmacokinetic studies of drugs in rodents are performed to predict efficacy and safety in humans. To date, humans are known to differ from model animals in terms of the composition, expression, and catalytic activity of drug-metabolizing enzymes and CYP isoforms. Particularly, CYP1A, CYP2C, CYP2D, and CYP3A subfamilies have exhibited considerable interspecies differences with respect to catalytic activity (Martignoni et al., 2016). Furthermore, gender differences in CYP2C (2C7, 2C11, 2C12, 2C13) and CYP3A isoforms (3A2, 3A9, 3A18) have been reported in rats (Martignoni et al., 2016). The question was whether these CYP isoforms are involved in GM metabolism.

More recently, we investigated the CYP isoforms involved in GM liver metabolism in males and females to elucidate the cause of gender differences of rat plasma GM pharmacokinetics (Kushida et al., 2021). When GM was reacted with the rat liver S9 fraction, the reduction of GM was more striking in the male S9 fraction $(69.3 \%)$ than in the female S9 fraction (10.0\%). Screening tests using recombinant rat CYP isoforms illustrated that CYP1A1, CYP2C6, CYP2C11, CYP2D1, and CYP3A2 were involved in GM metabolism. Of these CYP isoforms, male-dependent CYP2C11 and CYP3A2 were found to be predominantly involved in liver microsomal GM metabolism in experiments using anti-rat CYP antibodies. Although the GM metabolic pathway is the same in humans and rats (Kushida et al., 2015), the CYP isoforms involved in their metabolic pathways differ (Figure 2). In humans, GM was dehydrogenated and/or hydroxylated by CYP3A4, demethylated or hydrated by CYP2C19, and demethylated or hydroxylated by CYP2D6. These CYP isoforms reportedly exhibit no gender differences (Martignoni et al., 2016). Of these CYP isoforms, CYP3A4mediated hydroxylation is the major GM metabolic pathway (Matsumoto et al., 2016). However, in rats, CYP1A1, CYP2C6, CYP2C11, CYP2D1, or CYP3A2 are involved in GM metabolism. Of these CYP isoforms, CYP1A1, CYP2C6, and CYP2D1 are gender-independently expressed in the liver, whereas CYP2C11 and CYP3A2 are male-specific (Martignoni et al., 2016). The demethylation reaction for producing the GM metabolites M1$1 / 2$ was more active in male rats than in females, mainly controlled by CYP2C11 in males and CYP2D1 in females. Similarly, the M21 -producing dehydrogenation response mainly by CYP3A2 (males) and CYP1A1 (females), the M3-1/3-producing oxidation/dehydrogenation response by CYP3A2 (males) and CYP1A1 (females), and the M5-1/2-producing water addiction reaction by CYP2C11 (males) and CYP2D1 (females) were more dominant in male rats than in female rats. Regarding the M3-2producing oxidation/dehydrogenation and M4-1/2/3-producing oxidation reactions, CYP1A1 is involved in both sexes, and no 


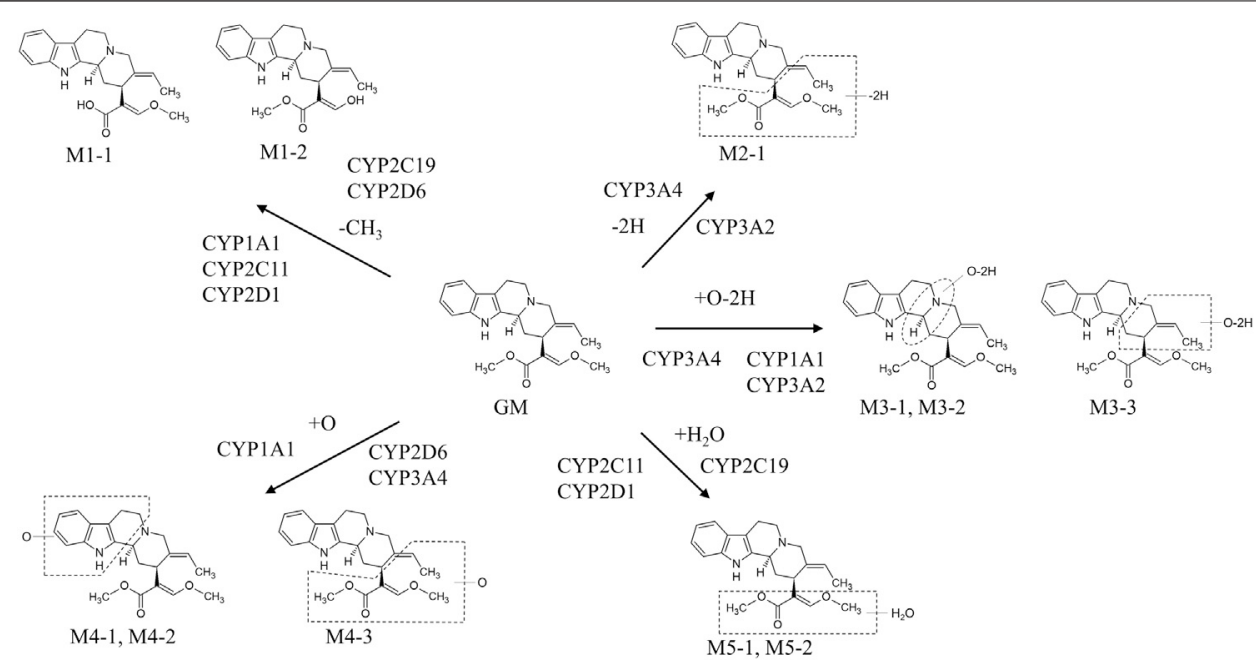

FIGURE 2 | In vitro metabolic pathways of GM in rat and human microsomes. The metabolic pathway of GM is the same in humans and rats (Kushida et al., 2015). However, the CYP isoforms involved in each metabolic pathway differ between humans and rats (Matsumoto et al., 2016; Kushida et al., 2021). In humans, GM was dehydrogenated and/or hydroxylated by CYP3A4, demethylated or hydrated by CYP2C19, and demethylated or hydroxylated by CYP2D6. Of these CYP isoforms, CYP3A4-mediated hydroxylation is the major pathway of GM metabolism (Matsumoto et al., 2016). In rats, GM was dehydrogenated and/or hydroxylated by CYP3A2, demethylated and dehydrogenated and/or hydroxylated by CYP1A1, demethylated, hydroxylated, and hydrated by CYP2C11, and demethylated and hydrated by CYP2D1 (Kushida et al., 2021).

gender-related difference could be observed in the case of these reactions. These results suggest that the cause of gender differences in plasma GM pharmacokinetics in rats is most likely because of male-dependent CYP2C11 and CYP3A2 activity. The findings should be useful for interpreting the pharmacological and toxicological effects of GM in the future.

CYP isoforms involved in the metabolism of ICX, RP, IRP, HTE, and HTI have been investigated (Nakazawa et al., 2006; Wang et al., 2010a; Wang et al., 2010b; Zhao et al., 2016b). Zhao et al. (2016b) estimated CYP isoforms involved in the production of the major metabolites of ICX, namely 18,19dehydrocorynoxinic acid and 5-oxo ICX, using recombinant human CYP isoforms. They found that CYP2C19 and CYP2D6 were involved in the production of 18,19dehydrocorynoxinic acid, and CYP3A4 was involved in the production of 5-oxo ICX. CYP isoforms involved in the 10and 11-hydroxylation of RP and IRP have also been inferred from studies using specific inhibitors in rat liver microsomes (Wang et al., 2010a; Wang et al., 2010b). The 10- and 11-hydroxylation of RP and IRP were inhibited by the addition of the specific inhibitors $a$-naphthoflavone (1A1/2), cimetidine (CYP2C), and quinine (CYP2D), but not by erythromycin (CYP3A). These results suggest that CYP1A1/2, CYP2C, and CYP2D, but not CYP3A, are involved in the 10- and 11-hydroxylation of RP and IRP. Similar inhibition studies using rat liver microsomes also suggested that CYP2C is involved in the 10- and 11hydroxylation of HTI and HTE (Nakazawa et al., 2006).

\section{Distribution}

\section{Exposure to Brain}

In addition to plasma, GM has also been detected in the brains of rats orally administered YKS (Imamura et al., 2011; Kushida et al.,
2013). Only GM was detected in the brains of male rats orally administered $4 \mathrm{~g} / \mathrm{kg}$ of YKS. $C_{\max }$ and $t_{\max }$ of GM were $1.18 \mathrm{ng} / \mathrm{g}$ and $0.5 \mathrm{~h}$, respectively (Kushida et al., 2013). The GM concentrations in the brains of female rats $1 \mathrm{~h}$ after the oral administration of 1 and $4 \mathrm{~g} / \mathrm{kg}$ of YKS were 1.6 and $5.9 \mathrm{ng} / \mathrm{g}$, respectively (Imamura et al., 2011). Concerning other crude drug products, only RP $\left(C_{\max }, 9.6 \mathrm{ng} / \mathrm{g} ; t_{\max }, 2 \mathrm{~h}\right)$ has been detected in the brains of rats orally administered a high dose $(25 \mathrm{~g} / \mathrm{kg})$ of Gouteng-Baitouweng (Tian et al., 2018).

It has been confirmed that some $\mathrm{UH}$ alkaloids can be transferred into the brain when pure drugs are administered (Wang et al., 2010b; Wang et al., 2016b; Wang et al., 2016 W; Zhang C. et al., 2019). CX was detected at a concentration of $11.8 \mathrm{ng} / \mathrm{g}\left(3.08 \times 10^{-11} \mathrm{~mol} / \mathrm{g}\right)$ in the brains of rats after oral administration at a dose of $40 \mathrm{mg} / \mathrm{kg}(0.105 \mathrm{~mol} / \mathrm{kg})$ (Wang W. et al., 2016). RP and IRP have also been detected in the brains of rats with $C_{\max }$ values of 16.96 and $7.35 \mathrm{ng} / \mathrm{g}$, respectively, after oral administration at a dose of $20 \mathrm{mg} / \mathrm{kg}$ (Zhang C. et al., 2019). Wang et al. (2010a) and Wang et al. (2010b) detected RP $(0.650 \mathrm{ng} / \mathrm{g})$ in the brains of rats orally administered RP $(37.5 \mathrm{mg} / \mathrm{kg})$. HTI was also identified in the rat brain after oral administration at a dose of $20 \mathrm{mg} / \mathrm{kg}$ (Wang et al., 2016b).

\section{BBB Permeability}

Furthermore, an in vitro BBB assay using a co-culture of primary rat brain endothelial cells, pericytes, and astrocytes (Nakagawa et al., 2007; Nakagawa et al., 2009) illustrated that the BBB permeability $(27.3 \%)$ of GM was approximately half that (52.0\%) of the antiepileptic drug carbamazepine but higher than those $(2.8-16.0 \%)$ of six Uncaria alkaloids, namely HTE, HTI, RP, IRP, CX, and ICX (Imamura et al., 2011). The BBB permeability of these six alkaloids has also been described in the 
MDCK-pHaMDR cell monolayer model (Zhang et al., 2017). These six alkaloids also permeabilized the $\mathrm{BBB}$, as reported by Imamura et al. (2011). Furthermore, an examination of BBB permeability using verapamil, a classical P-gp inhibitor, suggested that ICX, IRP, HTE, and HTI could cross the BBB, mainly by passive diffusion, whereas $\mathrm{CX}$ and $\mathrm{RP}$ cross the $\mathrm{BBB}$ via facilitated diffusion mediated by the excretion of P-gp.

These in vivo and in vitro findings suggest that plasma GM, along with other alkaloids, reaches the brain after passing through the BBB. However, the in vitro competitive binding assay of seven $\mathrm{UH}$-derived alkaloids to $5-\mathrm{HT}_{1 \mathrm{~A}}$ receptors showed that the $\mathrm{IC}_{50}$ value of GM for $\left[{ }^{3} \mathrm{H}\right] 8$-OH-DPAT was $0.904 \mu \mathrm{M}$, whereas the other alkaloids either had no competitive binding activity or exhibited $\mathrm{IC}_{50}$ values beyond $100 \mu \mathrm{M}$ (Nishi et al., 2012). Since the in vitro GM concentration was far from that in the brain (approximately 100-fold higher), the results of pharmacokinetic studies might not fully explain the pharmacological effects of GM. However, YKS or GM reportedly exhibit the pharmacological effects of improving aggressive behavior and restoring social behavior in mice treated with $1 \mathrm{~g} / \mathrm{kg}$ of YKS or $150 \mu \mathrm{g} / \mathrm{kg}$ of GM, equivalent to $1 \mathrm{~g} / \mathrm{kg}$ of YKS extract, respectively (Nishi et al., 2012).

\section{Brain Distribution}

In the previous sections, we suggested that oral GM definitely enters blood and reaches the brain via the BBB. In addition to this evidence, an in vitro autoradiography assay using [3H]GM revealed that GM specifically bound to various regions in normal brain slices; i.e., $\left[{ }^{3} \mathrm{H}\right] \mathrm{GM}$ bound to dopamine $\mathrm{D}_{2}$, adrenergic $\alpha_{2 \mathrm{~A}}$, and $\mu$-opioid receptors; L-type $\mathrm{Ca}^{2+}$ channels; and $5-\mathrm{HT}_{1 \mathrm{~A}}, 5-\mathrm{HT}_{2 \mathrm{~A}}, 5-\mathrm{HT}_{2 \mathrm{~B}}, 5-\mathrm{HT}_{2 \mathrm{C}}$, and $5-\mathrm{HT}_{7}$ receptors (Mizoguchi et al., 2014). Unfortunately, direct in vivo evidence of the distribution of GM in the brain remains to be produced. However, we recently demonstrated the brain distributions of GM and its hydroxylated metabolite (HM) in rats intravenously administered GM using DESI-MSI (Matsumoto et al., 2020), a powerful tool for visualizing the distributions of biomolecules in tissue sections (Fernandes et al., 2016). The ion images of GM in the brain sections demonstrated that GM was diffusely distributed throughout the brain parenchyma, including the cerebral cortex, hippocampus, striatum, thalamus, amygdala, and cerebellum. The combined results of DESI-MSI (Matsumoto et al., 2020) and autoradiography (Mizoguchi et al., 2014) suggest that GM is evenly distributed in brain regions and that it exerts pharmacological effects by binding to various channels and receptors. Furthermore, GM signals were detected in the cerebral ventricle even after the parenchymal signals had already disappeared. Contrarily, HM, the main metabolite of GM (Kushida et al., 2015; Matsumoto et al., 2016), was detected only in the ventricle after GM injection and not found in the brain parenchyma, suggesting that plasma HM may have entered cerebrospinal fluid (CSF) directly via the blood-CSF barrier (Strazielle and Ghersi-Egea, 2013) and not through the BBB (Laksitorini et al., 2014). CSF is produced in the choroid plexus, and it circulates in the cerebral ventricles. In addition, CSF is absorbed into the venous blood via arachnoid granulation, and it protrudes into the dural venous sinuses (Grzybowski et al., 2006). Therefore, it is assumed that GM and HM in CSF are also eventually excreted into venous blood through this system. The in vivo evidence of the distribution of GM in the brain (Matsumoto et al., 2020) strongly supports the hypothesis (Ikarashi and Mizoguchi, 2016; Ikarashi et al., 2018) that GM in plasma after the oral administration of YKS enters the brain via the BBB and distributes in various brain regions involved in behavioral and psychological symptoms.

As mentioned above, the distribution of GM in the brain, which is the target organ of GM, has been studied, but the transfer and distribution of GM and its metabolites to other organs have not been studied yet. It is necessary to investigate the organ migration and distribution of GM and its metabolites in order to better understand the safety and efficacy of GM. Therefore, it is expected that organ distribution studies of GM will be conducted in the future.

\section{Exposure in Other Organs}

Exposure to some UH alkaloids, including GM, in tissues other than brain has been investigated (Wang W. et al., 2016; Tian et al., 2018). The pharmacokinetic parameters of CX, ICX, RP, IRP, and GM in liver tissue following oral Gouteng-Baitouweng administration to rats at dose of $25 \mathrm{~g} / \mathrm{kg}$ were calculated as follows: AUC, 7,149.8, 248.6, 205.8, 4,295.8, and $210.6 \mathrm{ng} \mathrm{h} / \mathrm{g}$, respectively, $C_{\max }, 1,479.8,16.1,52.8,764.9$, and $29.1 \mathrm{ng} / \mathrm{g}$, respectively; and $t_{\max }, 1.0,1.0,1.0,1.0$, and $1.0 \mathrm{~h}$, respectively (Tian et al., 2018). In another study using pure CX, CX concentrations in the liver, heart, and kidneys $3 \mathrm{~h}$ after oral administration $(0.105 \mathrm{~mol} / \mathrm{kg})$ in rats were $6.38,8.37$, and 12.3 $\times 10-11 \mathrm{~mol} / \mathrm{g}$, respectively (Wang W. et al., 2016). Studying the exposure and time course of $\mathrm{UH}$ alkaloids in various organs will provide information on the accumulation of these components and contribute to clarification of the safety of UH alkaloidcontaining crude drug products.

\section{Excretion}

\section{Urinary Excretion}

Table 4 showed the excretion of UH alkaloids in urine and bile. $\mathrm{UH}$ alkaloids Two papers on the urinary excretion of GM have been reported. Gai et al. (2014) detected GM and its metabolite 18-hydroxy-GM in $8 \mathrm{~h}$ urine samples from mice orally administered YGS $(9.1 \mathrm{~g} / \mathrm{kg})$. Matsumoto et al. (2018) detected GM in urine samples collected during $24 \mathrm{~h}$ from mice orally administered YKS $(1 \mathrm{~g} / \mathrm{kg})$ in a basic study of drug-drug interactions between memantine and YKS. Furthermore, Gai et al. (2014) confirmed the urinary excretion of CX, ICX, RP, IRP, HTE, 11-hydroxy HTE, and 19-carbonyl HTI in addition to GM in mice orally treated with YGS.

As mentioned in the "Metabolism" sections, many metabolites of UH alkaloids are excreted in the urine and bile of rats and mice. Qi et al. (2015) identified 11-hydroxy ICX, 5-oxoisocorynoxeinic acid-22-O- $\beta$-D-glucuronide, 10-hydroxy ICX, 17-O-demethyl16,17-dihydro-5-oxo ICX, 5-oxoisocorynoxeinic acid, 21hydroxy-5-oxo ICX, oxireno[18, 19]-5-oxo ICX, 18,19dehydrocorynoxinic acid, 18,19-dehydrocorynoxinic acid B, $\mathrm{CX}$, ICX-N-oxide, and CX-N-oxide in rat urine following oral 
TABLE 4 | Excretion studies of UH alkaloids.

\begin{tabular}{|c|c|c|c|}
\hline Study type & Drug/Route/Animal & Detected compound & References \\
\hline \multirow{8}{*}{$\begin{array}{l}\text { Urinary } \\
\text { excretion }\end{array}$} & YGK $(9.1 \mathrm{~g} / \mathrm{kg})$, oral, mice & GM and its metabolite 18-hydroxy-GM were detected in $8 \mathrm{~h}$ urine samples & Gai et al. (2014) \\
\hline & YKS (1 g/kg), oral, mice & GM was detected in urine samples collected during $24 \mathrm{~h}$ & Matsumoto et al. (2018) \\
\hline & ICX (40 mg/kg), oral, rats & $\begin{array}{l}12 \text { metabolites: 11-hydroxy ICX, 5-oxoisocorynoxeinic acid-22-O- } \beta \text {-D- } \\
\text { glucuronide, 10-hydroxy ICX, 17-O-demethyl-16,17-dihydro-5-oxo ICX, 5- } \\
\text { oxoisocorynoxeinic acid, 21-hydroxy-5-oxo ICX, oxireno[18, 19]-5-oxo ICX, } \\
\text { 18,19-dehydrocorynoxinic acid, 18,19-dehydrocorynoxinic acid B, CX, ICX-N- } \\
\text { oxide, and CX-N-oxide }\end{array}$ & Qi et al. (2015) \\
\hline & ICX (40 mg/kg), oral, rats & $\begin{array}{l}33 \text { metabolites produced by hydrolysis, oxidation, isomerization, demethylation, } \\
\text { epoxidation, reduction, glucuronidation, hydroxylation, and } \mathrm{N} \text {-oxidation }\end{array}$ & Zhao et al. (2016a) \\
\hline & $\operatorname{IRP}(37.5 \mathrm{mg} / \mathrm{kg})$, oral, rats & 10- and 11-hydroxylated metabolites of IPR & Wang et al. (2010a) \\
\hline & $\mathrm{RP}(37.5 \mathrm{mg} / \mathrm{kg})$, oral, rats & 10- and 11-hydroxylated metabolites of RP & Wang et al. (2010b) \\
\hline & $\mathrm{IRP}$, oral, rats & $\begin{array}{l}47 \text { metabolites produced by dehydrogenation, oxidation, hydrolysis, reduction, } \\
\text { demethylation, hydroxylation and glucuronide conjugation }\end{array}$ & Wang et al. (2016a) \\
\hline & HTE and HTI (50 mg/kg), oal, rats & $\begin{array}{l}\text { 10- and 11-hydroxylated metabolites and 10- and 11-O- } \beta \text {-D-glucuronide } \\
\text { conjugates }\end{array}$ & Nakazawa et al. (2006) \\
\hline \multirow[t]{6}{*}{$\begin{array}{l}\text { Biliary } \\
\text { excretion }\end{array}$} & $\begin{array}{l}\text { Tianma-Gouteng Yin }(2.5 \text { and } \\
5 \mathrm{~g} / \mathrm{kg}) \text {, oral, rats }\end{array}$ & GM, CX, ICX, RP, IRP, HTE, and HTI & Zhan et al. (2017) \\
\hline & $\mathrm{CX}(0.105 \mathrm{mM} / \mathrm{kg})$, oral, rats & $\begin{array}{l}\text { 10-hydroxylated/10-O- } \beta \text {-D-glucuronide conjugates and 11-hydroxylated/11-O- } \\
\beta \text {-D-glucuronide conjugates }\end{array}$ & $\begin{array}{l}\text { Wang et al. (2014a) and Wang } \\
\text { et al. (2014b) }\end{array}$ \\
\hline & ICX (40 mg/k), oral, rats & $\begin{array}{l}\text { 10-hydroxylated/10-O- } \beta \text {-D-glucuronide conjugates and 11-hydroxylated/11-O- } \\
\beta \text {-D-glucuronide conjugates }\end{array}$ & Chen et al. (2014) \\
\hline & $\operatorname{IRP}(37.5 \mathrm{mg} / \mathrm{kg})$, oral, rats & $\begin{array}{l}\text { 10-hydroxylated/10-O- } \beta \text {-D-glucuronide conjugates and 11-hydroxylated/11-O- } \\
\beta \text {-D-glucuronide conjugates }\end{array}$ & Wang et al. (2010a) \\
\hline & $\mathrm{RP}(37.5 \mathrm{mg} / \mathrm{kg})$, oral, rats & $\begin{array}{l}\text { 10-hydroxylated/10-O- } \beta \text {-D-glucuronide conjugates and 11-hydroxylated/11-O- } \\
\beta \text {-D-glucuronide conjugates }\end{array}$ & Wang et al. (2010b) \\
\hline & HTE and HTI (50 mg/kg), oal, rats & $\begin{array}{l}\text { 10-hydroxylated/10-O- } \beta \text {-D-glucuronide conjugates and 11-hydroxylated/11-O- } \\
\beta \text {-D-glucuronide conjugates }\end{array}$ & Nakazawa et al. (2006) \\
\hline
\end{tabular}

ICX administration. In another study, 33 metabolites produced by hydrolysis, oxidation, isomerization, demethylation, epoxidation, reduction, glucuronidation, hydroxylation, and $\mathrm{N}$-oxidation were detected in the urine of rats orally treated with ICX (Zhao et al., 2016a). The 10- and 11-hydroxylated metabolites of RP and IPR have been detected in the urine of orally treated rats (Wang et al., 2010a; Wang et al., 2010b), and in other research, 47 metabolites of IRP were identified in the urine of rats (Wang J. et al., 2016). HTI and HTE were also excreted in rat urine as 10- and 11-hydroxylated metabolites and 10- and 11$O-\beta$-D-glucuronide conjugates (Nakazawa et al., 2006).

\section{Biliary Excretion}

Zhan et al. (2018) studied UH alkaloids excreted in the bile of rats orally treated with 2.5 and $5 \mathrm{~g} / \mathrm{kg}$ Tianma-Gouteng Yin granules. The major absorbed components were GM, CX, ICX, RP, IRP, HTE, and HTI in bile.

Similar UH alkaloid metabolites have been identified in urine and bile. Characteristically, the glucuronide conjugates of hydroxylated UH alkaloid metabolites are excreted in bile. For example, CX and ICX are excreted as 10-hydroxylated/10-O$\beta$-D-glucuronide conjugates and 11-hydroxylated/11-O- $\beta$-Dglucuronide conjugates in the bile of orally treated rats (Wang W. et al., 2014; Chen et al., 2014). Similar glucuronide metabolites have been identified and isolated from rat bile following the oral administration of RP, IRP, HTI, and HTE (Nakazawa et al., 2006; Wang et al., 2010a; Wang et al., 2010b). Although the biliary metabolites of GM have not been investigated, GM is metabolized to 10- and 11-hydroxylated metabolites, similarly as observed for other UH alkaloids (Kushida et al., 2015). Therefore, it is suggested that GM is also converted to $10-$ and 11hydroxylated metabolites and then excreted as 10- and 11-O$\beta$-D-glucuronide conjugates.

\section{DISCUSSION AND PERSPECTIVES}

The content of UH alkaloids in crude drug is not very high, and is even lower in the extracts of crude drug product (Nishi et al., 2012; Hou et al., 2018; Kushida et al., 2021). In addition, due to the unique properties of crude drug products, such as the pharmacokinetics of multicomponent and the low bioavailability of components, the unchanged components that appear in the circulating blood may be very low. Recent improvements in analytical techniques, especially in the sensitivity of mass spectrometers, have made it possible to quantify extremely low amounts of UH components in blood.

The LC-MS/MS methods for UH alkaloids are more sensitive than HPLC, with a wide linear range for the quantification of $\mathrm{UH}$ alkaloids (Table 1). For example, as discussed in the "Exposure to Blood" section, GM plasma concentration levels after oral administration of UH-containing crude drug products have been on the order of $\mathrm{ng} / \mathrm{ml}$. As the lower limit of quantification for GM using HPLC is approximately $0.5 \mu \mathrm{g} / \mathrm{ml}$, this method is not suitable for GM pharmacokinetic studies. The HPLC method seems to be suitable for the analysis of extracts with high content compounds, such as $\mathrm{UH}$-containing herbs or crude drug products. However, the LC-MS/MS lower limit of 
quantification in the plasma is $0.025-0.2 \mathrm{ng} / \mathrm{ml}$, which is optimal for GM pharmacokinetic studies. However, mass spectrometry sensitivity is known to be affected by the matrix of the sample; in the GM LC-MS/MS analytical method, the rat plasma matrix had little effect on its analytical sensitivity (Kushida et al., 2013; Tian et al., 2018), although the rat brain matrix exhibited a signal suppression of $53.0-55.5 \%$ to the GM analysis (Kushida et al., 2013). When analyzing GM in the brain tissue or that of other organs, an appropriate pretreatment method (e.g., solid-phase extraction) should be used to avoid the matrix effect. The MSI method using MALDI and DESI are very useful tools for visualizing the tissue distribution of components in herbs or crude drug products. MALDI-MSI and DESI-MSI ionize target compounds by applying laser and charged solvent spray, respectively. Therefore, the sensitivity of GM detection by MALDI-MSI and DESI-MSI is lower than that of LC-MS/ MS, and a large overdose compared to the normal dose is required to detect GM in the tissues. Most recently, an analytical technology has been developed with higher sensitivity than that of the conventional MALDI, which irradiates a second laser (Post-ionization laser). Such further breakthroughs in analytical techniques are essential to study the tissue distribution of GM at healthy doses.

One approach to investigating the absorption of a drug is to calculate its bioavailability by comparing the pharmacokinetic parameters between oral and intravenous administration. Chen et al. (2020) determined the bioavailability of six UH alkaloids, excluding GM, in mice. In another study, the bioavailability of HTI and HTE in rats was obtained (Han et al., 2019). The bioavailabilities of HTI and HTE (4.4 and $8.21 \%$ ) in mice were extremely different from those $(51.0 \%$, and $68.9 \%$ ) in rats, which displayed relatively low levels. This means that some UH alkaloids undergo different pharmacokinetic changes in different species. As discussed in the "Metabolism by CYPs in the Liver" section, male-specific CYP isoforms are involved in the metabolism of UH alkaloids in rats, and the plasma concentration of these agents are lower in males than in females (Kushida et al., 2021). In addition, gender-specific CYP isoforms are also expressed in the intestinal tract of rats, but they have not been identified in mice (Martignoni et al., 2016). Furthermore, the absorption and excretion of drugs may involve transporter proteins that are expressed in various organs such as the intestine, liver, and brain. For example, PEPT1 and OATP2B1 as influx transporter and P-gp and BCRP as efflux transporter were expressed in intestinal epithelial cells, and OATP1B1 and $1 \mathrm{~B} 3$ as influx transporter and MRP2 as efflux transporter were expressed in hepatocytes, respectively (Nakanishi and Tamai, 2015). It is also possible that the ability of transporters involved in the absorption and excretion of UH alkaloids may differ between rats and mice. These results suggest that the low bioavailability of $\mathrm{UH}$ alkaloids in rats are probably attributable to intestinal metabolic and absorption process. GM has not been investigated for bioavailability to date. The identification of metabolic enzymes and drug transporters would be useful for predicting drug-drug interactions. As discussed in the "Metabolism by CYPs in the Liver" section, the metabolic enzymes of UH alkaloids including GM have been identified, whereas their transporters have not been elucidated. It is difficult to predict whether transporters are involved in $\mathrm{UH}$ alkaloid uptake and excretion from the currently available data. Future strategies are needed to investigate the absorption of $\mathrm{UH}$ alkaloids, including their intestinal membrane permeability and efflux, and the involvement of transporters.

Because crude drug products are complex products consisting of two or more crude drugs, a single crude drug product may contain multiple components with different structures. These structures can affect the properties of the coexisting components through physical and chemical interactions. Hence, the results of pharmacokinetic studies using crude drug products may differ significantly from those using pure drugs. In a pharmacokinetic study of rats administered YGS, MRT, CL/F, and V/F were $7.25 \mathrm{~h}$, $2.72 \mathrm{~L} \mathrm{~h} / \mathrm{kg}$, and $39.79 \mathrm{~L} / \mathrm{kg}$, respectively, for $\mathrm{RP}$ and $7.82 \mathrm{~h}, 6.65 \mathrm{~L}$ $\mathrm{h} / \mathrm{kg}$, and $83.73 \mathrm{~L} / \mathrm{kg}$, respectively, for ICX (Gai et al., 2014). Comparing these results with those of a pharmacokinetic study using pure drug-administered mice (Chen et al., 2020), MRTs of RP and ICX in YGS were approximately 5 -fold longer than those of the pure drug (1.7 and $1.6 \mathrm{~h}$, respectively), and $\mathrm{CL} / \mathrm{F}$ and $\mathrm{V} / \mathrm{F}$ (11.6 and $8.2 \mathrm{~L} \mathrm{~h} / \mathrm{kg} ; 60.1$ and $45.7 \mathrm{~L} / \mathrm{kg}$ ) were approximately 3-4fold smaller. Furthermore, considering the approximately 10 -fold greater bioavailability in mice than in rats, $\mathrm{CL} / \mathrm{F}$ and V/F of YGS were 30-40-fold smaller. These results support the pharmacokinetic differences between crude and pure drug formulations. However, there is a lack of evidence to confirm this phenomenon. It is expected that further research will be conducted to determine the cause of the differences in pharmacokinetics between crude drug products and pure drugs.

Traditional Japanese Kampo medicines are clinically administered between meals. This might explain why research on the impact of food on the efficacy of Kampo medicines, including crude UH-containing drug products such as YKS and $\mathrm{YKSCH}$, and the absorption of their ingredients is scarce. Because GM is an alkaloid with a $\log P$ of 3.445 and $\mathrm{pKa}$ of 8.25 , it is expectedly absorbed in the weakly alkaline small intestine but not in the strongly acidic stomach. In fact, the GM absorption time was relatively short, displaying a $t_{\max }$ of $1-2 \mathrm{~h}$. Meals could affect $\mathrm{pH}$ changes in the stomach and the subsequent elimination of GM. Therefore, the absorption of GM is potentially influenced by meals. Other UH alkaloids may also be influenced by meals due to their similar physical properties.

Previous metabolic studies of GM have been conducted only in the liver, suggesting that CYP1A, CYP2C, CYP2D, and CYP3A isoforms are involved in the metabolism of GM. CYP3A isoforms are also known to be present in the intestinal tract. As GM is administered orally, the intestinal tract may be the first-pass organ. Therefore, CYP3A expressed in the intestinal tract might be responsible for the observed gender-related GM plasma concentration differences in rats. CYP3A is only involved in dehydrogenation and dehydrogenation/hydroxylation in rats. Assuming that the main metabolic pathway in rats is hydroxylation as in humans, which is probably highly likely, the contribution of CYP3A to the gender-related differences might not be that high, since CYP1A1 is responsible for hydroxylation in rats. However, GM intestinal metabolism has not yet been investigated. Detailed studies on GM metabolism in 
the intestine, including the identification of CYPs involved in metabolism, contribution ratio to metabolism, and metabolic stability, would probably clarify the gender-related differences and major organs involved in GM metabolism in rats.

As mentioned in the "Metabolism" sections, UH alkaloids are converted into various metabolites such as hydroxylated and demethylated metabolites. Among the metabolic pathways of these metabolites, the main metabolic pathways are probably 10 - and 11-hydroxylation followed by 10 - and 11-O- $\beta$-Dglucuronide conjugation, as metabolites produced by these reactions were isolated from the urine, feces, and bile of rats administered UH alkaloids. CYP1A1/2, CYP2C, and CYP2D are involved in this hydroxylation in rats, and CYP3A4 and CYP2D6 participate in this process in humans. In addition, CYP2C11 and CYP3A2 have been revealed to participate in demethylation and dehydrogenation based on the results of identification studies of rat CYP isoforms related to GM metabolism. These rat CYP isoforms are expressed in a male-specific manner, which results in gender differences in circulating GM concentrations in rats. Although no gender differences in the rat blood concentrations of UH alkaloids other than GM have been reported till date, gender differences in the blood concentrations of UH alkaloids are expected to occur in rats. Information on the metabolites of $\mathrm{UH}$ alkaloids and the enzymes involved in their metabolism will be useful for further pharmacological studies of UH-containing crude drug products and the prediction of drug-drug interactions in clinical use.

When the clinical doses of YKS were orally administered to rats, RP, HTI, HTE, and GM were detected in circulating plasma, and only GM was detected in the brain (Kushida et al., 2013). In in vivo studies using pure alkaloids such as CX, RP, IRP and HTI, these were also detected in the brain (Wang et al., 2010b; Wang et al., 2016b; Wang et al., 2016 W; Zhang C. et al., 2019). However, these doses are $20-40 \mathrm{mg} / \mathrm{kg}$, which is $200-1000$ fold higher than the content in YKS (Nishi et al., 2012). Thus, $\mathrm{UH}$ alkaloids, excluding GM, can be detected in the brain when administered at doses 200-1000-fold higher than the clinical dose, but they are undetectable when the dose of the crude drug products is close to the clinical dose. In addition, YKS or GM reportedly exhibit the pharmacological effects of improving aggressive behavior and restoring social behavior in mice treated with $1 \mathrm{~g} / \mathrm{kg}$ of YKS or $150 \mu \mathrm{g} / \mathrm{kg}$ of $\mathrm{GM}$, equivalent to $1 \mathrm{~g} / \mathrm{kg}$ of YKS extract, respectively (Nishi et al., 2012). These results suggest that GM is probably the main pharmacological component of UH-containing crude drug products at clinical doses. However, since the effective concentration of GM in in vitro studies was far from GM concentration in the brain (approximately 100-fold higher) (Nakagawa et al., 2012; Nishi et al., 2012; Kanno et al., 2014; Ishida et al., 2016), the results of pharmacokinetic studies might not fully explain the pharmacological effects of GM. GM was shown to be converted to metabolites, such as oxidized and demethylated metabolites. Hydroxylated metabolites have been identified as GM metabolites in the brain (Matsumoto et al., 2020), although other metabolites in the brain have not been investigated yet. Furthermore, whether GM metabolites exhibit a pharmacological activity has not yet been investigated. However, details regarding the brain exposure and distribution of $\mathrm{UH}$ alkaloid metabolites and their pharmacological activities have not yet been investigated, and these activities may be responsible for the pharmacological effects. Therefore, relevant studies are needed in the future. Future identification of UH alkaloids metabolites in the brain and their pharmacological studies would help to resolve the discrepancy between pharmacological and brain concentrations.

\section{CONCLUSION}

In recent years, the development of analytical techniques has permitted pharmacokinetic studies of UH-containing alkaloids. Among the UH-containing alkaloids, GM is an alkaloid with strong pharmacological activity. GM appears rapidly in the blood after oral administration and passes through the BBB to the target organ, the brain. GM is metabolized by hepatic CYP isoforms to metabolites such as demethylated, dehydrogenated, and hydroxylated forms. Other $\mathrm{UH}$ alkaloids follow the same in vivo fate as GM. Observation of the pharmacokinetics of $\mathrm{UH}$ alkaloids is extremely important for understanding the pharmacological activity, efficacy, and safety of UH-containing drug treatments. However, although pharmacokinetic studies of $\mathrm{UH}$ alkaloids have progressed, they are inadequate, and further studies are needed to clarify certain issues, such as the effects of food on $\mathrm{UH}$ alkaloid absorption, the excretion profile of the metabolites of the alkaloids, their metabolism in intestinal tissues, and differences in pharmacokinetics between crude drug products and pure drugs. These aspects would potentially provide a better understanding of $\mathrm{UH}$-containing crude drug product efficacy and safety.

\section{AUTHOR CONTRIBUTIONS}

YI conceptualized the manuscript. YI and HK collected the literature and wrote the manuscript. HK prepared the figures and tables. HK, TM, and YI reviewed and edited the manuscript. All authors contributed to the article and approved the submitted version.

\section{FUNDING}

The authors declare that this study received funding from Tsumura \& Co. The funder was not involved in the study design, collection, analysis, interpretation of data, the writing of this article or the decision to submit it for publication, which are completely the responsibilities of the authors.

\section{ACKNOWLEDGMENTS}

For studies conducted at Tsumura Research Laboratories, the authors thank the following researchers and managers for 
planning the studies, performing the experiments, analyzing the data, writing the papers, and for stimulating discussion: Toshiyuki Ueki, Zenji Kawakami, Masahiro Tabuchi, Sachiko Imamura, Akinori Nishi, Hitomi Kanno, Takuji Yamaguchi,

\section{REFERENCES}

Chen, L.-L., Song, J.-X., Lu, J.-H., Yuan, Z.-W., Liu, L.-F., Durairajan, S. S. K., et al. (2014). Corynoxine, a Natural Autophagy Enhancer, Promotes the Clearance of Alpha-Synuclein via Akt/mTOR Pathway. J. Neuroimmune Pharmacol. 9, 380-387. doi:10.1007/s11481-014-9528-2

Chen, L., Ma, J., Wang, X., and Zhang, M. (2020). Simultaneous Determination of Six Uncaria Alkaloids in Mouse Blood by UPLC-MS/MS and its Application in Pharmacokinetics and Bioavailability. Biomed. Res. Int. 2020, 1-11. doi:10.1155/2020/1030269

Chua, K. K., Chau, C. C., and Li, M. (2012). Experimental and Clinical Research Literature Review of Tianma Gouteng Yin on the Treatment of Parkinson's Disease. Hong Kong J. Tradi. Chin. Med. 7, 66-70.

Egashira, N., Mishima, K., Kurauchi, K., Iwasaki, K., and Fujiwara, M. (2001). Cholinergic Involvement in the Improving Effects of Yoku-Kan-San-KaChimpi-Hange (Yi-Gan-San- Jia-Chen-Pi-Ban-Xia) on the Disruption of Spatial Cognition and the Electroconvulsive Shock-Induced Immobilization. J. Trad. Med. 18, 71-80.

Fernandes, A. M. A. P., Vendramini, P. H., Galaverna, R., Schwab, N. V., Alberici, L. C., Augusti, R., et al. (2016). Direct Visualization of Neurotransmitters in Rat Brain Slices by Desorption Electrospray Ionization Mass Spectrometry Imaging (DESI - MS). J. Am. Soc. Mass. Spectrom. 27, 1944-1951. doi:10.1007/s13361016-1475-0

Fu, A. K. Y., Hung, K.-W., Huang, H., Gu, S., Shen, Y., Cheng, E. Y. L., et al. (2014). Blockade of EphA4 Signaling Ameliorates Hippocampal Synaptic Dysfunctions in Mouse Models of Alzheimer's Disease. Proc. Natl. Acad. Sci. USA. 111, 9959-9964. doi:10.1073/pnas.1405803111

Gai, Y., Chen, H., Liu, W., Feng, F., and Xie, N. (2014). The Metabolism of YiGan San and Subsequent Pharmacokinetic Evaluation of Four Metabolites in Rat Based on Liquid Chromatography with Tandem Mass Spectrometry. J. Chromatogr. B 972, 22-28. doi:10.1016/j.jchromb.2014.09.033

Giordano, S., Zucchetti, M., Decio, A., Cesca, M., Fuso Nerini, I., Maiezza, M., et al. (2016). Heterogeneity of Paclitaxel Distribution in Different Tumor Models Assessed by MALDI Mass Spectrometry Imaging. Sci. Rep. 6, 39284. doi:10.1038/srep39284

Grzybowski, D. M., Holman, D. W., Katz, S. E., and Lubow, M. (2006). In Vitro model of Cerebrospinal Fluid Outflow through Human Arachnoid Granulations. Invest. Ophthalmol. Vis. Sci. 47, 3664-3672. doi:10.1167/ iovs.05-0929

Han, A., Lin, G., Cai, J., Wu, Q., Geng, P., Ma, J., et al. (2019). Pharmacokinetic Study on Hirsutine and Hirsuteine in Rats Using UPLC-MS/MS. Acta Chromatographica 31, 99-104. doi:10.1556/1326.2017.00365

Hou, J., Feng, R., Zhang, Y., Pan, H., Yao, S., Han, S., et al. (2018). Characteristic Chromatogram: a Method of Discriminate and Quantitative Analysis for Quality Evaluation of Uncaria Stem with hooks. Planta Med. 84, 449-456. doi:10.1055/s-0043-123827

Ikarashi, Y., and Mizoguchi, K. (2016). Neuropharmacological Efficacy of the Traditional Japanese Kampo Medicine Yokukansan and its Active Ingredients. Pharmacol. Ther. 166, 84-95. doi:10.1016/j.pharmthera.2016.06.018

Ikarashi, Y., Sekiguchi, K., and Mizoguchi, K. (2018). Serotonin Receptor Binding Characteristics of Geissoschizine Methyl Ether, an Indole Alkaloid in Uncaria Hook. Cmc 25, 1036-1045. doi:10.2174/0929867324666170320114713

Imamura, S., Tabuchi, M., Kushida, H., Nishi, A., Kanno, H., Yamaguchi, T., et al. (2011). The Blood-Brain Barrier Permeability of Geissoschizine Methyl Ether in Uncaria Hook, a Galenical Constituent of the Traditional Japanese Medicine Yokukansan. Cell Mol. Neurobiol. 31, 787-793. doi:10.1007/s10571-011-9676-3

Ishida, Y., Ebihara, K., Tabuchi, M., Imamura, S., Sekiguchi, K., Mizoguchi, K., et al. (2016). Yokukansan, a Traditional Japanese Medicine, Enhances the L-DOPAInduced Rotational Response in 6-Hydroxydopamine-Lesioned Rats: Possible
Kyoji Sekiguchi, Hiroaki Ooizumi, Nae Kuriyama, Junko Watanabe, Tomohisa Hattori, and Yoshio Kase. The authors would like to thank Enago (http://www.enago.jp) for the English language review.

Inhibition of COMT. Biol. Pharm. Bull. 39, 104-113. doi:10.1248/bpb.b1500691

Ishikawa, A., Makino, K., Idezuka, J., and Kuwabara, T. (2006). Improvement of Symptoms Following Epileptic Convulsion in a Patient with Parkinson's Disease. Mov. Disord. 21, 1055. doi:10.1002/mds.20885

Ito, A., Shin, N., Tsuchida, T., Okubo, T., and Norimoto, H. (2013). Antianxietylike Effects of Chimpi (Dried Citrus Peels) in the Elevated Open-Platform Test. Molecules 18, 10014-10023. doi:10.3390/molecules180810014

Jiang, P., Chen, L., Sun, J., Li, J., Xu, J., Liu, W., et al. (2019). Chotosan Ameliorates Cognitive Impairment and hippocampus Neuronal Loss in Experimental Vascular Dementia via Activating the Nrf2-Mediated Antioxidant Pathway. J. Pharmacol. Sci. 139, 105-111. doi:10.1016/j.jphs.2018.12.003

Kanno, H., Kawakami, Z., Mizoguchi, K., Ikarashi, Y., and Kase, Y. (2014). Yokukansan, a Kampo Medicine, Protects PC12 Cells from GlutamateInduced Death by Augmenting Gene Expression of Cystine/Glutamate Antiporter System Xc-. PLoS One 9, e116275. doi:10.1371/ journal.pone.0116275

Kawakami, Z., Ikarashi, Y., and Kase, Y. (2011). Isoliquiritigenin Is a Novel NMDA Receptor Antagonist in Kampo Medicine Yokukansan. Cel Mol. Neurobiol. 31, 1203-1212. doi:10.1007/s10571-011-9722-1

Kim, T.-J., Lee, J.-H., Lee, J.-J., Yu, J.-Y., Hwang, B.-Y., Ye, S.-K., et al. (2008). Corynoxeine Isolated from the Hook of Uncaria Rhynchophylla Inhibits Rat Aortic Vascular Smooth Muscle Cell Proliferation through the Blocking of Extracellular Signal Regulated Kinase 1/2 Phosphorylation. Biol. Pharm. Bull. 31, 2073-2078. doi:10.1248/bpb.31.2073

Kitagawa, H., Munekage, M., Ichikawa, K., Fukudome, I., Munekage, E., Takezaki, Y., et al. (2015). Pharmacokinetics of Active Components of Yokukansan, a Traditional Japanese Herbal Medicine after a Single Oral Administration to Healthy Japanese Volunteers: a Cross-Over, Randomized Study. PLoS One 10, e0131165. doi:10.1371/journal.pone.0131165

Kushida, H., Fukutake, M., Tabuchi, M., Katsuhara, T., Nishimura, H., Ikarashi, Y., et al. (2013). Simultaneous Quantitative Analyses of Indole and Oxindole Alkaloids of Uncaria Hook in Rat Plasma and Brain after Oral Administration of the Traditional Japanese Medicine Yokukansan Using High-Performance Liquid Chromatography with Tandem Mass Spectrometr. Biomed. Chromatogr. 27, 1647-1656. doi:10.1002/bmc.2974

Kushida, H., Matsumoto, T., Igarashi, Y., Nishimura, H., Watanabe, J., Maemura, K., et al. (2015). Metabolic Profiling of the Uncaria Hook Alkaloid Geissoschizine Methyl Ether in Rat and Human Liver Microsomes Using High-Performance Liquid Chromatography with Tandem Mass Spectrometry. Molecules 20, 2100-2114. doi:10.3390/molecules20022100

Kushida, H., Matsumoto, T., Ikarashi, Y., Nishimura, H., and Yamamoto, M. (2021). Gender Differences in Plasma Pharmacokinetics and Hepatic Metabolism of Geissoschizine Methyl Ether from Uncaria Hook in Rats. J. Ethnopharmacology 264, 113354. doi:10.1016/j.jep.2020.113354

Laksitorini, M., Prasasty, V. D., Kiptoo, P. K., and Siahaan, T. J. (2014). Pathways and Progress in Improving Drug Delivery through the Intestinal Mucosa and Blood-Brain Barriers. Ther. Deliv. 5, 1143-1163. doi:10.4155/tde.14.67

Li, X.-M., Zhang, X.-J., and Dong, M.-X. (2017). Isorhynchophylline Attenuates MPP+-Induced Apoptosis through Endoplasmic Reticulum Stress- and Mitochondria-dependent Pathways in PC12 Cells: Involvement of Antioxidant Activity. Neuromol Med. 19, 480-492. doi:10.1007/s12017-0178462-X

Liang, J.-H., Wang, C., Huo, X.-K., Tian, X.-G., Zhao, W.-Y., Wang, X., et al. (2020). The Genus Uncaria: A Review on Phytochemical Metabolites and Biological Aspects. Fitoterapia 147, 104772. doi:10.1016/j.fitote.2020.104772

Liu, L.-F., Song, J.-X., Lu, J.-H., Huang, Y.-Y., Zeng, Y., Chen, L.-L., et al. (2015). Tianma Gouteng Yin, a Traditional Chinese Medicine Decoction, Exerts Neuroprotective Effects in Animal and Cellular Models of Parkinson's Disease. Sci. Rep. 5, 16862. doi:10.1038/srep16862 
Lu, J.-H., Tan, J.-Q., Durairajan, S. S. K., Liu, L.-F., Zhang, Z.-H., Ma, L., et al. (2012). Isorhynchophylline, a Natural Alkaloid, Promotes the Degradation of Alpha-Synuclein in Neuronal Cells via Inducing Autophagy. Autophagy 8, 98-108. doi:10.4161/auto.8.1.18313

Ma, B., Wang, J., Sun, J., Li, M., Xu, H., Sun, G., et al. (2014). Permeability of Rhynchophylline across Human Intestinal Cell In Vitro. Int. J. Clin. Exp. Pathol. 7, 957-966.

Martignoni, M., Groothuis, G. M. M., and de Kanter, R. (2006). Species Differences between Mouse, Rat, Dog, Monkey and Human CYP-Mediated Drug Metabolism, Inhibition and Induction. Expert Opin. Drug Metab. Toxicol. 2, 875-894. doi:10.1517/17425255.2.6.875

Matsumoto, K., Zhao, Q., Niu, Y., Fujiwara, H., Tanaka, K., Sasaki-Hamada, S., et al. (2013). Kampo Formulations, Chotosan, and Yokukansan, for Dementia Therapy: Existing Clinical and Preclinical Evidence. J. Pharmacol. Sci. 122, 257-269. doi:10.1254/jphs.13R03CR

Matsumoto, T., Ikarashi, Y., Takiyama, M., Watanabe, J., and Setou, M. (2020). Brain Distribution of Geissoschizine Methyl Ether in Rats Using Mass Spectrometry Imaging Analysis. Sci. Rep. 10, 7293. doi:10.1038/s41598-02063474-x

Matsumoto, T., Kushida, H., Maruyama, T., Nishimura, H., Watanabe, J., Maemura, K., et al. (2016). In Vitroidentification of Human Cytochrome P450 Isoforms Involved in the Metabolism of Geissoschizine Methyl Ether, an Active Component of the Traditional Japanese Medicine Yokukansan. Xenobiotica 46, 325-334. doi:10.3109/00498254.2015.1076585

Matsumoto, T., Kushida, H., Matsushita, S., Oyama, Y., Suda, T., Watanabe, J., et al. (2017). Distribution Analysis via Mass Spectrometry Imaging of Ephedrine in the Lungs of Rats Orally Administered the Japanese Kampo Medicine Maoto. Sci. Rep. 7, 44098. doi:10.1038/srep44098

Matsumoto, T., Sekiguchi, K., Kawakami, Z., Watanabe, J., Mizoguchi, K., Ikarashi, Y., et al. (2018). Basic Study of Drug-Drug Interaction between Memantine and the Traditional Japanese Kampo Medicine Yokukansan. Molecules 24, 115. doi:10.3390/molecules 24010115

Ministry of Health, Labour, and Welfare MHLW (2016). Japanese Pharmacopoeia 17th Edition: the MHLW Ministerial Notification No. 64. Availableat: https:// www.mhlw.go.jp/file/06-Seisakujouhou-11120000-Iyakushokuhinkyoku/ JP17_REV.pdf.

Mizoguchi, K., and Ikarashi, Y. (2017). Cellular Pharmacological Effects of the Traditional Japanese Kampo Medicine Yokukansan on Brain Cells. Front. Pharmacol. 8, 655. doi:10.3389/fphar.2017.00655

Mizoguchi, K., Kushida, H., Kanno, H., Igarashi, Y., Nishimura, H., Ikarashi, Y., et al. (2014). Specific Binding and Characteristics of Geissoschizine Methyl Ether, an Indole Alkaloid of Uncaria Hook, in the Rat Brain. J. Ethnopharmacology 158, 264-270. doi:10.1016/j.jep.2014.10.015

Murakami, Y., Zhao, Q., Harada, K., Tohda, M., Watanabe, H., and Matsumoto, K. (2005). Choto-san, a Kampo Formula, Improves Chronic Cerebral Hypoperfusion-Induced Spatial Learning Deficit via Stimulation of Muscarinic M Receptor. Pharmacol. Biochem. Behav. 81, 616-625. doi:10.1016/j.pbb.2005.05.004

Nakagawa, S., Deli, M. A., Kawaguchi, H., Shimizudani, T., Shimono, T., Kittel, Á., et al. (2009). A New Blood-Brain Barrier Model Using Primary Rat Brain Endothelial Cells, Pericytes and Astrocytes. Neurochem. Int. 54, 253-263. doi:10.1016/j.neuint.2008.12.002

Nakagawa, S., Deli, M. A., Nakao, S., Honda, M., Hayashi, K., Nakaoke, R., et al. (2007). Pericytes from Brain Microvessels Strengthen the Barrier Integrity in Primary Cultures of Rat Brain Endothelial Cells. Cell. Mol. Neurobiol. 27, 687-694. doi:10.1007/s10571-007-9195-4

Nakagawa, T., Nagayasu, K., Nishitani, N., Shirakawa, H., Sekiguchi, K., Ikarashi, Y., et al. (2012). Yokukansan Inhibits Morphine Tolerance and Physical Dependence in Mice: The Role of a2A-adrenoceptor. Neuroscience 227, 336-349. doi:10.1016/j.neuroscience.2012.09.079

Nakanishi, T., and Tamai, I. (2015). Interaction of Drug or Food with Drug Transporters in Intestine and Liver. $C d m$ 16, 753-764. doi:10.2174/ 138920021609151201113537

Nakatani, Y., Amano, T., Yamamoto, H., Sakai, N., Tsuji, M., and Takeda, H. (2017). Yokukansan Enhances the Proliferation of B65 Neuroblastoma. J. Traditional Complement. Med. 7, 34-44. doi:10.1016/j.jtcme.2016.01.006

Nakazawa, T., Banba, K.-i., Hata, K., Nihei, Y., Hoshikawa, A., and Ohsawa, K. (2006). Metabolites of Hirsuteine and Hirsutine, the Major Indole Alkaloids of
Uncaria Rhynchophylla, in Rats. Biol. Pharm. Bull. 29, 1671-1677. doi:10.1248/ bpb.29.1671

Ndagijimana, A., Wang, X., Pan, G., Zhang, F., Feng, H., and Olaleye, O. (2013). A Review on Indole Alkaloids Isolated from Uncaria Rhynchophylla and Their Pharmacological Studies. Fitoterapia 86, 35-47. doi:10.1016/j.fitote.2013.01.018

Nishi, A., Yamaguchi, T., Sekiguchi, K., Imamura, S., Tabuchi, M., Kanno, H., et al. (2012). Geissoschizine Methyl Ether, an Alkaloid in Uncaria Hook, Is a Potent serotonin1A Receptor Agonist and Candidate for Amelioration of Aggressiveness and Sociality by Yokukansan. Neuroscience 207, 124-136. doi:10.1016/j.neuroscience.2012.01.037

Pengsuparp, T., Indra, B., Nakagawasai, O., Tadano, T., Mimaki, Y., Sashida, Y., et al. (2001). Pharmacological Studies of Geissoschizine Methyl Ether, Isolated from Uncaria Sinensis Oliv., in the central Nervous System. Eur. J. Pharmacol. 425, 211-218. doi:10.1016/S0014-2999(01)01195-5

Qi, W., Chen, F., Sun, J., Simpkins, J., and Yuan, D. (2015). Isolation and Identification of Twelve Metabolites of Isocorynoxeine in Rat Urine and Their Neuroprotective Activities in HT22 Cell Assay. Planta Med. 81, 46-55. doi:10.1055/s-0034-1383357

Qi, W., Yue, S.-J., Sun, J.-H., Simpkins, J. W., Zhang, L., and Yuan, D. (2014). Alkaloids from the Hook-Bearing branch ofUncariarhynchophyllaand Their Neuroprotective Effects against Glutamate-Induced HT22 Cell Death. J. Asian Nat. Prod. Res. 16, 876-883. doi:10.1080/10286020.2014.918109

Sakakibara, I., Terabayashi, S., Kubo, M., Higuchi, M., Komatsu, Y., Okada, M., et al. (1999). Effect on Locomotion of Indole Alkaloids from the hooks of Uncaria Plants. Phytomedicine 6, 163-168. doi:10.1016/S0944-7113(99) 80004-X

Strazielle, N., and Ghersi-Egea, J. F. (2013). Physiology of Blood-Brain Interfaces in Relation to Brain Disposition of Small Compounds and Macromolecules. Mol. Pharmaceutics 10, 1473-1491. doi:10.1021/mp300518e

Sun, J., Ren, X., Qi, W., Yuan, D., and Simpkins, J. W. (2016). Geissoschizine Methyl Ether Protects Oxidative Stress-Mediated Cytotoxicity in Neurons through the 'Neuronal Warburg Effect'. J. Ethnopharmacology 187, 249-258. doi:10.1016/j.jep.2016.04.034

Tabuchi, M., Mizuno, K., Mizoguchi, K., Hattori, T., and Kase, Y. (2017). Yokukansan and Yokukansankachimpihange Ameliorate Aggressive Behaviors in Rats with Cholinergic Degeneration in the Nucleus Basalis of Meynert. Front. Pharmacol. 8, 235. doi:10.3389/fphar.2017.00235

Takiyama, M., Matsumoto, T., and Watanabe, J. (2019). LC-MS/MS Detection of Citrus Unshiu Peel-Derived Flavonoids in the Plasma and Brain after Oral Administration of Yokukansankachimpihange in Rats. Xenobiotica 49, 1494-1503. doi:10.1080/00498254.2019.1581300

Tian, X., Xu, Z., Chen, M., Hu, P., Liu, F., Sun, Z., et al. (2018). Simultaneous Determination of Eight Bioactive Compounds by LC-MS/MS and its Application to the Pharmacokinetics, Liver First-Pass Effect, Liver and Brain Distribution of Orally Administrated Gouteng-Baitouweng (GB) in Rats. J. Chromatogr. B 1084, 122-131. doi:10.1016/j.jchromb.2018.03.013

Tsuji, M., Takeuchi, T., Miyagawa, K., Ishii, D., Imai, T., Takeda, K., et al. (2014). Yokukansan, a Traditional Japanese Herbal Medicine, Alleviates the Emotional Abnormality Induced by Maladaptation to Stress in Mice. Phytomedicine 21, 363-371. doi:10.1016/j.phymed.2013.08.025

Ueda, T., Ugawa, S., Ishida, Y., and Shimada, S. (2011). Geissoschizine Methyl Ether Has Third-Generation Antipsychotic-like Actions at the Dopamine and Serotonin Receptors. Eur. J. Pharmacol. 671, 79-86. doi:10.1016/ j.ejphar.2011.09.007

Ueki, T., Nishi, A., Imamura, S., Kanno, H., Mizoguchi, K., Sekiguchi, K., et al. (2013). Effects of Geissoschizine Methyl Ether, an Indole Alkaloid in Uncaria Hook, a Constituent of Yokukansan, on Human Recombinant Serotonin7 Receptor. Cell Mol Neurobiol 33, 129-135. doi:10.1007/s10571-012-9878-3

Wang, H.-B., Qi, W., Zhang, L., and Yuan, D. (2014a). Qualitative and Quantitative Analyses of Alkaloids in Uncaria Species by UPLC-ESI-Q-TOF/MS. Chem. Pharm. Bull. 62, 1100-1109. doi:10.1248/cpb.c14-00481

Wang, J., Qi, P., Hou, J., Shen, Y., Yan, B., Bi, Q., et al. (2016a). Profiling and Identification of Metabolites of Isorhynchophylline in Rats by Ultra High Performance Liquid Chromatography and Linear Ion Trap Orbitrap Mass Spectrometry. J. Chromatogr. B 1033-1034, 147-156. doi:10.1016/ j.jchromb.2016.08.013

Wang, J., Qi, P., Hou, J., Shen, Y., Yang, M., Bi, Q., et al. (2017b). The Profiling of the Metabolites of Hirsutine in Rat by Ultra-high Performance Liquid 
Chromatography Coupled with Linear Ion Trap Orbitrap Mass Spectrometry: An Improved Strategy for the Systematic Screening and Identification of Metabolites in Multi-Samples In Vivo. J. Pharm. Biomed. Anal. 134, 149-157. doi:10.1016/j.jpba.2016.11.034

Wang, W., Li, X., Chen, Y., and Hattori, M. (2014b). Structural Elucidation of Rat Biliary Metabolites of Corynoxeine and Their Quantification Using LC-MSn. Biomed. Chromatogr. 28, 1219-1228. doi:10.1002/bmc.3149

Wang, W., Luo, S., Chen, Y., Li, B., and Hattori, M. (2016c). Effective Separation and Simultaneous Determination of Corynoxeine and its Metabolites in Rats by High-Performance Liquid Chromatography with Tandem Mass Spectrometry and Application to Pharmacokinetics and In Vivo Distribution in Main Organs. Anal. Sci. 32, 705-707. doi:10.2116/analsci.32.705

Wang, W., Ma, C.-M., and Hattori, M. (2010b). Metabolism and Pharmacokinetics of Rhynchophylline in Rats. Biol. Pharm. Bull. 33, 669-676. doi:10.1248/ bpb.33.669

Wang, W., Ma, C.-M., and Hattori, M. (2010a). Metabolism of Isorhynchophylline in Rats Detected by LC-MS. J. Pharm. Pharm. Sci. 13, 27-37. doi:10.18433/ j33g60

Wang, X., Zheng, M., Liu, J., Huang, Z., Bai, Y., Ren, Z., et al. (2017). Differences of First-Pass Effect in the Liver and Intestine Contribute to the Stereoselective Pharmacokinetics of Rhynchophylline and Isorhynchophylline Epimers in Rats. J. Ethnopharmacology 209, 175-183. doi:10.1016/j.jep.2017.07.039

Watanabe, H., Zhao, Q., Matsumoto, K., Tohda, M., Murakami, Y., Zhang, S.-H., et al. (2003). Pharmacological Evidence for Antidementia Effect of Choto-San (Gouteng-San), a Traditional Kampo Medicine. Pharmacol. Biochem. Behav. 75, 635-643. doi:10.1016/s0091-3057(03)00109-6

Xian, Y.-F., Fan, D., Ip, S.-P., Mao, Q.-Q., and Lin, Z.-X. (2017). Antidepressantlike Effect of Isorhynchophylline in Mice. Neurochem. Res. 42, 678-685. doi:10.1007/s11064-016-2124-5

Xian, Y.-F., Lin, Z.-X., Mao, Q.-Q., Hu, Z., Zhao, M., Che, C.-T., et al. (2012). Bioassay-Guided Isolation of Neuroprotective Compounds fromUncaria Rhynchophyllaagainst Beta-Amyloid-Induced Neurotoxicity. Evidence-Based Complement. Altern. Med. 2012, 1-8. doi:10.1155/2012/802625

Yang, W., Ip, S.-P., Liu, L., Xian, Y.-F., and Lin, Z.-X. (2020). Uncaria Rhynchophylla and its Major Constituents on central Nervous System: a Review on Their Pharmacological Actions. Cvp 18, 346-357. doi:10.2174/ 1570161117666190704092841

Yuzurihara, M., Ikarashi, Y., Goto, K., Sakakibara, I., Hayakawa, T., and Sasaki, H. (2002). Geissoschizine methyl ether, an indole alkaloid extracted from Uncariae Ramulus et Uncus, is a potent vasorelaxant of isolated rat aorta. Eur. J. Pharmacol. 444, 183-189. doi:10.1016/s0014-2999(02)01623-0

Zhang, C., Wu, X., Xian, Y., Zhu, L., Lin, G., and Lin, Z.-X. (2019a). Evidence on Integrating Pharmacokinetics to Find Truly Therapeutic Agent for Alzheimer's
Disease: Comparative Pharmacokinetics and Disposition Kinetics Profiles of Stereoisomers Isorhynchophylline and Rhynchophylline in Rats. EvidenceBased Complement. Altern. Med. 2019, 1-9. doi:10.1155/2019/4016323

Zhang, H., Duan, S., Wang, L., Liu, J., Qi, W., and Yuan, D. (2019b). Identification of the Absorbed Components and Their Metabolites of Tianma-Gouteng Granule in Rat Plasma and Bile Using Ultra-high-performance Liquid Chromatography Combined with Quadrupole Time-Of-Flight Mass Spectrometry. Biomed. Chromatogr. 33, e4480. doi:10.1002/bmc.4480

Zhang, Q., Zhao, J. J., Xu, J., Feng, F., and Qu, W. (2015). Medicinal Uses, Phytochemistry and Pharmacology of the Genus Uncaria. J. Ethnopharmacology 173, 48-80. doi:10.1016/j.jep.2015.06.011

Zhang, Y.-N., Yang, Y.-F., Xu, W., and Yang, X.-W. (2017). The Blood-Brain Barrier Permeability of Six Indole Alkaloids from Uncariae Ramulus Cum Uncis in the MDCK-pHaMDR Cell Monolayer Model. Molecules 22, 1944. doi:10.3390/molecules22111944

Zhao, L., Qi, W., Chen, F., Sun, J., and Yuan, D. (2016a). Metabolic Profile of Isocorynoxeine in Rats Obtained by Ultra-high Performance Liquid Chromatography/quadrupole Time-Of-Flight Mass Spectrometry. Eur. J. Drug Metab. Pharmacokinet. 41, 615-626. doi:10.1007/s13318-015-0287-0

Zhao, L., Zang, B., Qi, W., Chen, F., Wang, H., Kano, Y., et al. (2016b). Pharmacokinetic Study of Isocorynoxeine Metabolites Mediated by Cytochrome P450 Enzymes in Rat and Human Liver Microsomes. Fitoterapia 111, 49-57. doi:10.1016/j.fitote.2016.04.008

Zhao, Q., Murakami, Y., Tohda, M., Watanabe, H., and Matsumoto, K. (2005). Preventive Effect of Chotosan, a Kampo Medicine, on Transient IschemiaInduced Learning Deficit Is Mediated by Stimulation of Muscarinic M1 but Not Nicotinic Receptor. Biol. Pharm. Bull. 28, 1873-1878. doi:10.1248/ bpb.28.1873

Conflict of Interest: Authors HK, TM and YI are employees of Tsumura \& Co. The authors declare that, except for income provided in the form of salaries from the employers, no financial support or compensation has been received from any individual or corporate entity.

The reviewer YU declared a past co-authorship with one of the author TM to the handling editor.

Copyright (c) 2021 Kushida, Matsumoto and Ikarashi. This is an open-access article distributed under the terms of the Creative Commons Attribution License (CC BY). The use, distribution or reproduction in other forums is permitted, provided the original author(s) and the copyright owner(s) are credited and that the original publication in this journal is cited, in accordance with accepted academic practice. No use, distribution or reproduction is permitted which does not comply with these terms. 